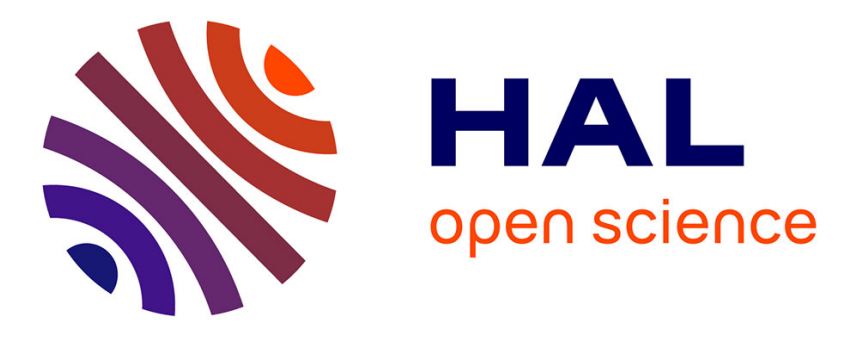

\title{
Thermo-oxidation behaviour of organic matrix composite materials at high temperatures
}

Jacques Cinquin, Xavier Colin, Bruno Fayolle, Marion Mille, Svetlana

Terekhina, Laurence Chocinski-Arnault, Marco Gigliotti, Jean-Claude

Grandidier, Marie-Christine Lafarie-Frénot, Matteo Minervino, et al.

\section{To cite this version:}

Jacques Cinquin, Xavier Colin, Bruno Fayolle, Marion Mille, Svetlana Terekhina, et al.. Thermooxidation behaviour of organic matrix composite materials at high temperatures. Advances in Aircraft and Spacecraft Science, 2016, 3 (2), pp.171-195. 10.12989/aas.2016.3.2.171 . hal-01392502

\section{HAL Id: hal-01392502 \\ https://hal.science/hal-01392502}

Submitted on 4 Nov 2016

HAL is a multi-disciplinary open access archive for the deposit and dissemination of scientific research documents, whether they are published or not. The documents may come from teaching and research institutions in France or abroad, or from public or private research centers.
L'archive ouverte pluridisciplinaire HAL, est destinée au dépôt et à la diffusion de documents scientifiques de niveau recherche, publiés ou non, émanant des établissements d'enseignement et de recherche français ou étrangers, des laboratoires publics ou privés. 


\title{
Thermo-oxidation behaviour of organic matrix composite materials at high temperatures
}

\author{
Jacques Cinquin ${ }^{* 1}$, Xavier Colin², Bruno Fayolle ${ }^{2}$, Marion Mille ${ }^{2}$, Svetlana Terekhina ${ }^{2}$, \\ Laurence Chocinski-Arnault ${ }^{3}$, Marco Gigliotti ${ }^{3}$, Jean-Claude Grandidier ${ }^{3}$, \\ Marie-Christine Lafarie-Frenot ${ }^{3}$, Matteo Minervino ${ }^{3}$, Christophe Cluzel $^{4}$, \\ Federica Daghia ${ }^{4}$, Pierre Ladeveze ${ }^{4}$ and Fangzouh Zhang $^{4}$ \\ ${ }^{1}$ Airbus Group Innovations, 12 rue Pasteur, 92152 Suresnes, France \\ ${ }^{2}$ Laboratoire PIMM (UMR CNRS 8006), Art et Métiers ParisTech, 151 Boulevard de l'Hôpital, \\ 75013 Paris, France \\ ${ }^{3}$ Institut Pprime, CNRS - ENSMA - Université de Poitiers, UPR 3346, ISAE-ENSMA, 1, avenue Clément \\ Ader, BP 40109, F86961 FUTUROSCOPE CHASSENEUIL Cedex, France \\ ${ }^{4}$ LMT, ENS Cachan, CNRS, Université Paris Saclay), 61 avenue du Président Wilson, \\ 94235 Cachan Cedex, France
}

\begin{abstract}
The present paper is a review of the main activities carried out within the context of the COMPTINN' program, a joint research project founded by a FUI program (Fonds Unifiés Interministériels) in which four research teams focused on the thermo-oxidation behaviour of HTS-TACTIX carbon-epoxy composite at 'high' temperatures $\left(120^{\circ} \mathrm{C}-180^{\circ} \mathrm{C}\right)$. The scientific aim of the COMPTINN' program was to better identify, with a multi-scale approach, the link between the physico-chemical mechanisms involved in thermo-oxidation phenomena, and to provide theoretical and numerical tools for predicting the mechanical behaviour of aged composite materials including damage onset and development.
\end{abstract}

Keywords: polymer matrix composites; environmental degradation; thermo-oxidation; epoxy resin; micro indentation; delamination

\section{Introduction}

In last generation civil aircraft such as A350 or B787, composite materials represent more than $50 \%$ of the structural weight of the aircraft. Main areas of the structure are now made from composite materials (wing, fuselage, central wing box). All these parts are loaded mainly in 2D and are certified for service temperature below $100^{\circ} \mathrm{C}$. The next step, if we want to introduce more composite in the structure, is to develop application for 3D loaded parts and for parts working in the temperature range $120^{\circ} \mathrm{C}-180^{\circ} \mathrm{C}$. Durability and thermo-oxidation on long term (more than 80000 hours) are the main points to address. Thermo-oxidation of composite materials made of thermoset polymer reinforced with carbon fibres involves many physical and chemical 
mechanisms that initiate modifications in the polymer matrix. These modifications induce variations of mechanical behaviour and alterations of use properties at different scales (matrix, individual ply and laminate) leading to the degradation of the composite material. These mechanisms depend on environmental parameters such as exposure time, temperature, partial oxygen pressure, mechanical loading and composite micro-structure. Therefore, the long term exposure to 'high' temperature $\left(120^{\circ} \mathrm{C}-180^{\circ} \mathrm{C}\right)$ has a major influence on the composite structure durability (Lafarie-Frenot et al. 2010).

Thermo-oxidation of organic composite materials is identified as the result of oxygen diffusion inside the material coupled with the oxidation reaction of the polymer matrix (Dayile and Quintana 2013), which induces mainly chain scissions leading to variation of mechanical properties (Putthanarat et al. 2008), change of the material microstructure promoting spontaneous cracks onset (Lafarie-Frenot et al. 2006): damage facilitates oxygen penetration promoting the development of thermo-oxidation inside the material (Schoeppner et al. 2007). Physico-chemical and mechanical mechanisms are then strongly coupled.

A consistent literature exists concerning the physical-chemical (Tandon and Schoeppner 2006), Olivier et al. 2008) and thermo-chemical-mechanical (Minervino et al. 2013 within COMPTINN), (Olivier 2008) phenomena induced by thermo-oxidation in polymer and composite materials, at the molecular (Dayile and Quintana 2013, Bellenger and Verdu 1985, Colin et al. 2005), microscopic (Olivier et al 2008), (Minervino et al. 2013 within COMPTINN), (Gigliotti et al. 2011), (Minervino et al. 2015 within COMPTINN) and mesoscopic (Daghia and Cluzel 2013 within COMPTINN), (Daghia and Cluzel 2014 within COMPTINN), (VU et al. 2012 within COMPTINN), (Lubineau and Ladeveze 2008), (Daghia et al. 2015 within COMPTINN) scales.

Despite the richness of the collected information, all this research work presents only partial aspects of thermo-oxidation in composites and develops method and model which are specific to a given scale/application. So far, no unitary approach exists which could be capable of collecting all the methods, at different scales. Such approach is of benefit since it is not possible to exhaustively understand physical phenomena occurring at a given scale, without proper knowledge of phenomena occurring at other scales. At the same time, the strongly coupled feature of thermooxidation in polymer composite requires multiple skills and expertise in different fields of study, including physical-chemistry, mechanics of materials and structural mechanics without ignoring the technical/technological aspects related to the development of new products which are expected to suffer from ageing issues during their life.

The understanding and modelling of the complex phenomena which determine the thermooxidation aging require multiple expertises. For this reason, the 'COMPTINN' project consortium involved an industrial partner (Airbus Group Innovation), as well as researchers from different fields, ranging from polymer chemistry (PIMM laboratory) to structural mechanics (LMT laboratory), through micromechanical modelling and characterization (Pprime Institute). This project started in October 2010 and ended in May 2014.

The proposed approach to elaborate a predictive model for the prediction of composite material durability under thermo-oxidative environment consists in:

- Observing the effects induced by thermo-oxidation at different scales;

- Analysing the influence of environmental parameters (exposure time, temperature, relative oxygen pressure, composite micro-structure, mechanical loading) on thermo-oxidation;

- Proposing, identifying and validating proposed coupled multi-physics models at different scales;

The understanding of the behaviour of the composite, however, is not so linear; a continuous 
exchange of information is required between experiments and modelling at the different scales.

Section 2 presents the material and the manufacturing process. Section 3 illustrates the main effects induced by thermo-oxidation on polymers and polymer matrix composites. Section 4 focuses on the description of the main parameters affecting thermo-oxidation induced degradation in polymers and polymer matrix composites. Section 5 presents the multi-physical coupled models used to interpret the experimental tests. Finally, Section 6 wraps up the work with conclusions and perspectives, in particular focusing on the missing information and blocking points which still need to be investigated. The ultimate aim of this study is to propose a strategy for simulating and predicting durability of polymer matrix composites subjected to thermo-oxidative degradation.

\section{Materials and manufacturing process}

In this work, we have used a composite material based on an epoxy-diamine matrix from Huntsmann. The polymer network results from the reaction of a mixture of 54 wt $\%$ of trifunctional epoxy monomer (Tactix 742, CAS 66072-38-6) and 18 wt $\%$ of di-functional epoxy monomer (Tactix 123, CAS 1675-54-3) by 28 wt $\%$ of a di-functional amine hardener (Aradur 9664-1, CAS 80-08-0, melting point around $\left.174-178^{\circ} \mathrm{C}\right)$. Thereafter, we will name this formulation "Tactix" for simplification.

A unidirectional prepreg has been manufactured by CTMI company using the Tactix resin and high resistance carbon fibre HTS from Toho Tenax. The area weight of the manufactured prepreg is $223 \mathrm{~g} / \mathrm{m}^{2}$ with $34 \mathrm{wt} \%$ of resin content and $147 \mathrm{~g} / \mathrm{m}^{2}$ of dry fibre weight per unit area. The curing cycle consists of three dwells $\left(1\right.$ hour at $140^{\circ} \mathrm{C}, 3$ hours at $180^{\circ} \mathrm{C}$ and 1 hour at $250^{\circ} \mathrm{C}$ ). A pressure of 7 bars and a vacuum of 0.9 bars are applied during all the curing cycle to minimize the porosity content of the resulting laminates. In order to obtain a fully cured composite, we have optimized the post-cure conditions. The glass transition temperature $(T g)$ has been determined by Dynamic Mechanical Analysis (DMA) (based on the maximum $\tan \delta$ peak) on pure resin sample after different post cure cycles applied additionally to the curing cycle. A post-cure of 10 hours at

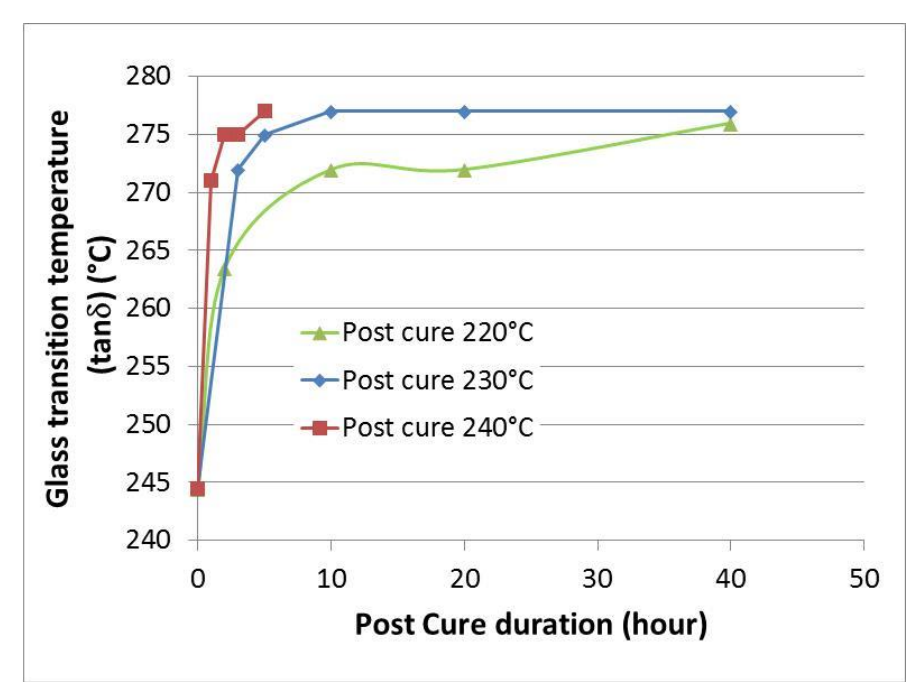

Fig. 1 Evolution of $T g$ with post-cure temperature and duration by DMA for unreinforced Tactix samples 
$230^{\circ} \mathrm{C}$ under vacuum has been selected based on the results presented in Fig. 1. The resulting $T g$ is around $277^{\circ} \mathrm{C}$.

\section{Induced effects}

In this section, the effects induced by thermo-oxidation are experimentally investigated at different scales: on thin films and thick samples of neat Tactix polymer, and on unidirectional ply and laminated HTS carbon fibres/Tactix composite.

\subsection{Polymer/unreinforced matrix}

The first step consists in identifying the oxidation products associated with the chain scission process. This chain scission process is responsible for Young's modulus increase and for embrittlement of the oxidized layer. In a first approach, thermal oxidation is performed on thin film (100 $\mu \mathrm{m}$ thick) in order to avoid diffusion limited oxidation (DLO), oxidation can be thus considered as homogeneous throughout the thickness sample. As a result, the thin film can be viewed as the superficial layer of thick samples.

In order to identify and follow the formation of oxidation products during exposure, the infrared spectrophotometer appears as the best apparatus. As an example, Fig. 2 shows the changes in the chemical composition of thin Tactix films at $150^{\circ} \mathrm{C}$ in air. Significant modifications are observed in the IR spectrum from the early periods of exposure: new peaks appear at 1725, 1680 and $1660 \mathrm{~cm}^{-1}$ and grow rapidly against time of exposure. The peak at $1725 \mathrm{~cm}^{-1}$ is attributed to carbonyl groups $(C=\mathrm{O})$. Knowing the initial chemical structure of Tactix polymer, these carbonyl groups are associated to a chain scission process induced by oxidation occurring in the hydroxypropylether segment at the crosslinks vicinity (Bellenger and Verdu 1985).

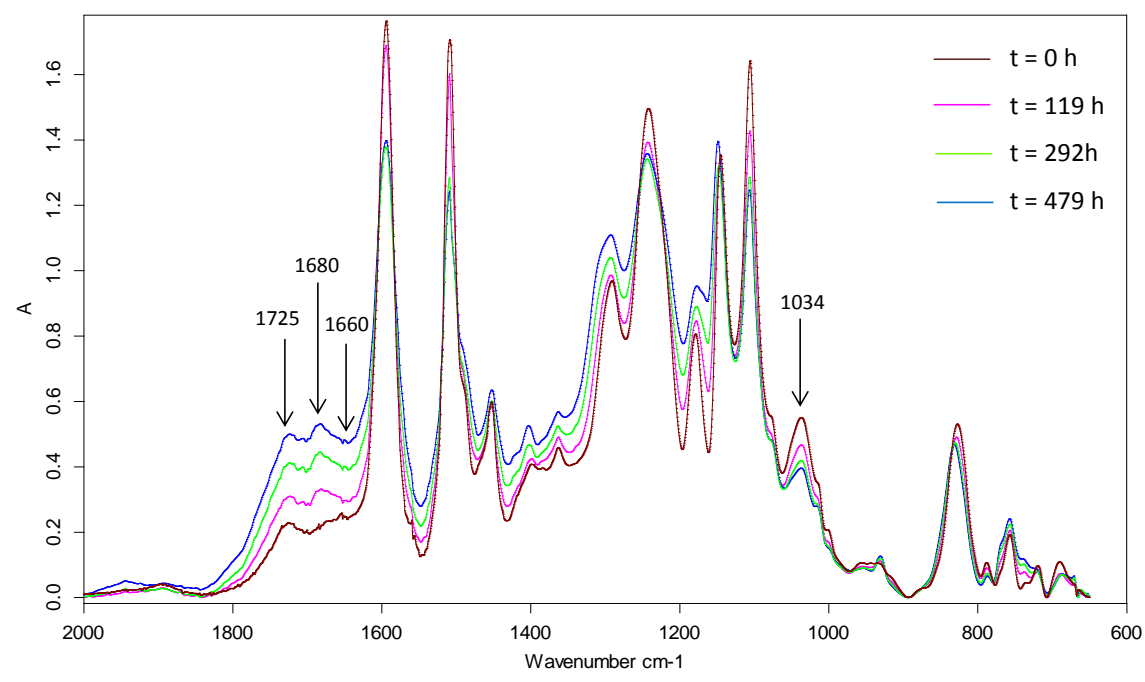

Fig. 2 Changes in the chemical composition of thin Tactix films during their thermal aging. Infra-red spectra after different exposure durations at $150^{\circ} \mathrm{C}$ in air. The arrows indicate absorption bands relative to carbonyl $\left(1725 \mathrm{~cm}^{-1}\right)$ and amide groups (1680 and $\left.1660 \mathrm{~cm}^{-1}\right)$, but also to substrate $\left(1034 \mathrm{~cm}^{-1}\right)$ 


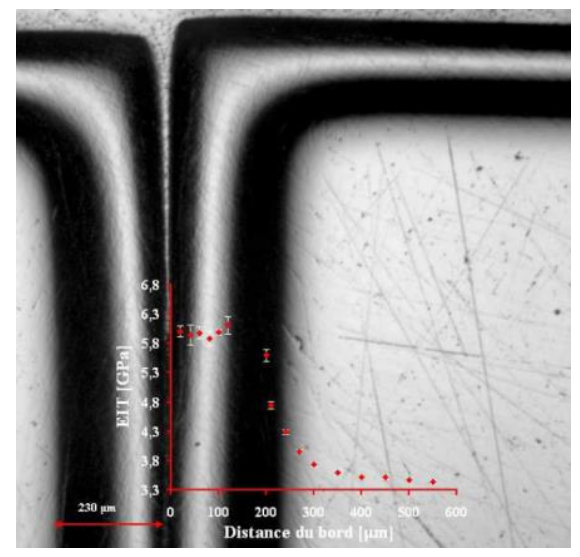

(a) Indentation curves at various distances from the edge exposed to the environment

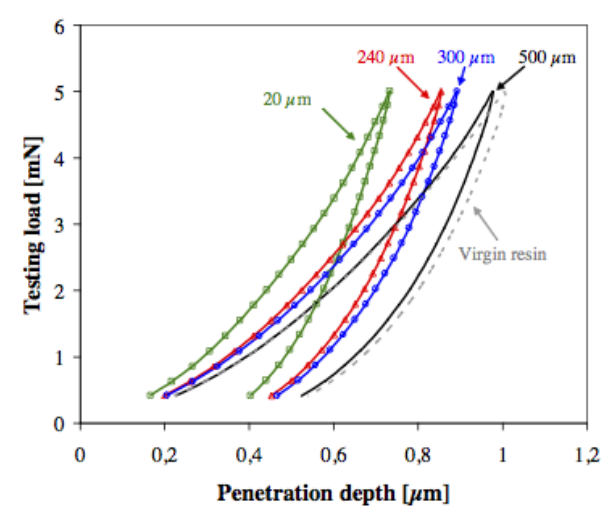

(b) Aging conditions: $120 \mathrm{~h}$ under 2 bars of oxygen at $150^{\circ} \mathrm{C}$

Fig. 3 Observation of the oxidized layer by light microscopy and superimposition of the corresponding EIT profile

As a result, oxidation modifies not only the molecular structure, but also the macromolecular architecture of the polymer network. Oxygen grafting along the polymer chains leads to a density increase, whereas chain scissions near the chain extremities generate a high amount of volatile products leading ultimately to a mass loss.

On thick polymer samples, the DLO leads to an oxidized surface layer (Fig. 3(a)) whose thickness varies in a more or less significant way with the testing conditions (temperature, partial oxygen pressure, duration ...). More precisely, this oxidized layer corresponds to the material area in which a competition takes place between the oxygen diffusion and its chemical consumption by the oxidation reaction (Tandon et al. 2006, Colin et al. 2001, Bowles et al. 1993). This layer can be characterized by optical microscopy (Colin et al, 2001, Bowles et al. 2001), white light interferometry (Putthanarat et al. 2007), atomic force microscopy (Johnson et al. 2003), pinpoint DMA (Dole and Chauchard 1995) and instrumented ultra-micro-indentation (Olivier et al. 2008), the two latter techniques enabling to study the local evolution of mechanical properties inside the oxidized layer. For example, in Fig. 3(a), the measured values of the elastic modulus of indentation (EIT) correspond to measurement points shown on the image of the oxidized layer obtained by optical microscopy: this overlay enables us to view the steep gradient of elastic modulus that is present in this layer. Concerning more generally the evolution of mechanical properties with oxidation, the changes in the Tactix polymer behaviour throughout the sample thickness can be observed in Fig. 3(b), through the curves of 'load vs penetration depth' obtained by instrumented Ultra-Micro-Indentation (UMI). Fig. 3(b) shows clearly that oxidation modifies the mechanical behaviour, which results in an increase in the elastic modulus when approaching the outer surface of the specimen (Minervino et al. 2013).

To understand why a mechanism of chain scissions leads to an increase in elastic modulus, Dynamical Mechanical Analysis (DMA) tests were performed on "thick" samples - therefore having an oxidation gradient - aged for different durations at $150^{\circ} \mathrm{C}$ under 2 bars of oxygen. The DMA test consists in following the storage and loss moduli during a temperature ramp from $-140^{\circ} \mathrm{C}$ to $300^{\circ} \mathrm{C}$. For a non-oxidized specimen (initial state), the variations of storage modulus $E^{\prime}$ (Fig. 4(a)) and loss modulus $E^{\prime \prime}$ (Fig. 4(b)) show a main transition (denoted $\alpha$ ) related to the glass 


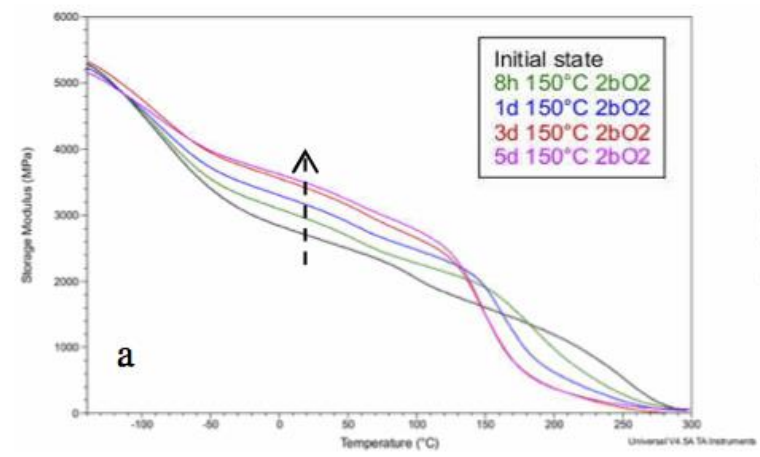

(a) Storage modulus.

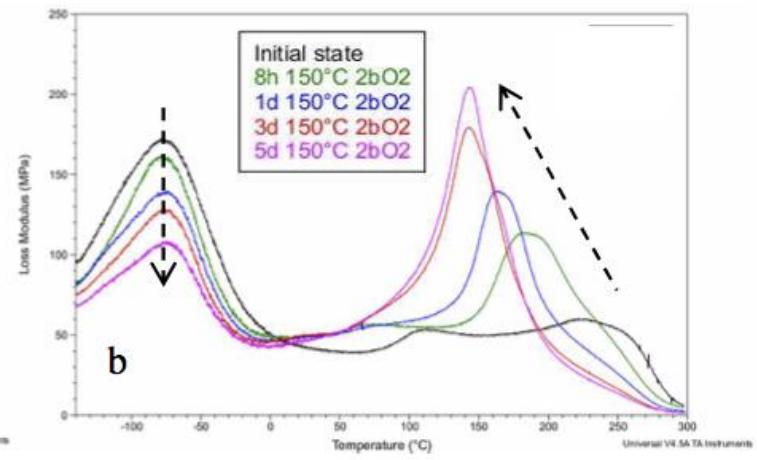

(b) Loss modulus.

Fig. 4 DMA spectra of TACTIX polymer for different oxidation levels: from initial state up to 5 days of aging under 2 bars of oxygen at $150^{\circ} \mathrm{C}$

transition and a secondary one (denoted $\beta$ ) lying around $-70^{\circ} \mathrm{C}$. As the oxidation time increases, there is a decrease in the intensity of the secondary transition $\beta$ (Fig. 4 (b)), while the temperature of the main transition $\alpha$ shifts towards lower temperatures (typically $150^{\circ} \mathrm{C}$ after three days of exposure). The changes in viscoelastic behaviour lead to an increase in the storage modulus at room temperature (Fig. 4 (a)), confirming the increase of the elastic modulus of indentation EIT observed in Fig. 3 (a).

This mechanism is often called 'antiplasticization' (Rasoldier et al. 2008). The occurrence of chain scissions induces a decrease in the glass transition temperature and local mobility (characterized by the transition $\beta$ ), and thus induces also an increase in the modulus in the domain ranged between the temperatures of the main $(T \alpha)$ and secondary transition $(T \beta)$. However, it must be noted that, since the diffusion-reaction process leads to an oxidized superficial layer, the DMA test only reflects the changes in mechanical properties of a heterogeneous sample, i.e. composed of a non-oxidized core and two superficial layers in which the properties vary. Therefore, the measured values of $E^{\prime}, E^{\prime \prime}, \tan \delta \ldots$ on DMA curves of an oxidized "thick" sample cannot be interpreted without the help of a multilayers model. In the case of much thicker samples, and in some configurations, this heterogeneous aspect can result in the doubling of peak $\alpha$ (ChocinskiArnault et al. 2009). In the case presented here, there is instead a convolution of peaks related to the different oxidation levels.

In parallel with the increase in modulus at room temperature, oxidation and associated chain scissions result in a shrinkage phenomenon (called chemical shrinkage thereafter) and an embrittlement of the polymer matrix. Chemical shrinkage can be inferred from variations in density and mass (spatial and temporal) during the oxidation of a thick polymer sample, whereas embrittlement is related to the polymer network characterized by a decrease in crosslinking density.

All these modifications lead to a spontaneous cracking at the free surface of thick samples. Fig. 5 shows the penetration of the oxidation front towards the sample core at $200^{\circ} \mathrm{C}$ in air. A superficial oxidized layer of about $200 \mu \mathrm{m}$ thickness is formed after about 1000 hours of exposure. After about 3000 hours, this oxidized layer cracks. It is noteworthy that the crack propagates throughout the oxidized layer and stops by blunting when reaching the non-oxidized core, thus allowing oxygen penetration into deeper layers. Thenceforth, a new oxidized layer, having the 


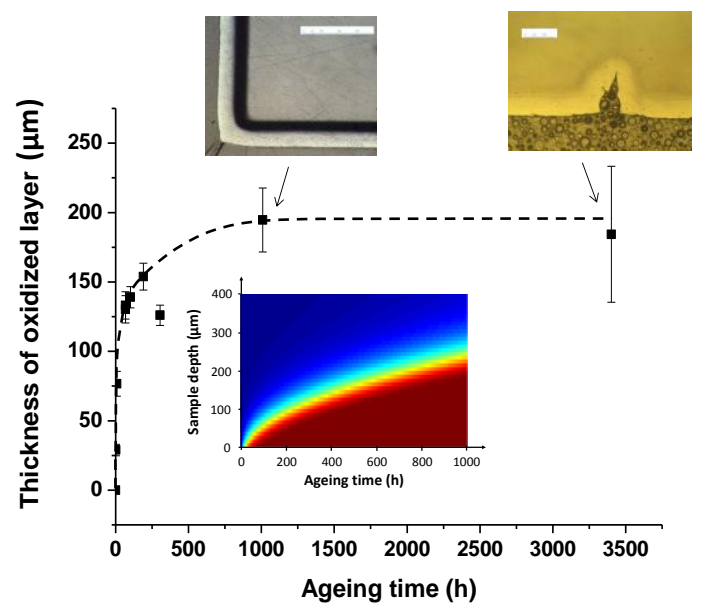

Fig. 5 Thickness of oxidized layer as a function of time at $200^{\circ} \mathrm{C}$ in air. Top: Examination by optical microscopy of the sample edges after about 1000 and 3000 hours respectively. The oxidized layer appears lighter and brighter than the sample core. Bottom: Simulation of the penetration of the oxidation front (in red) towards the sample core (in blue)
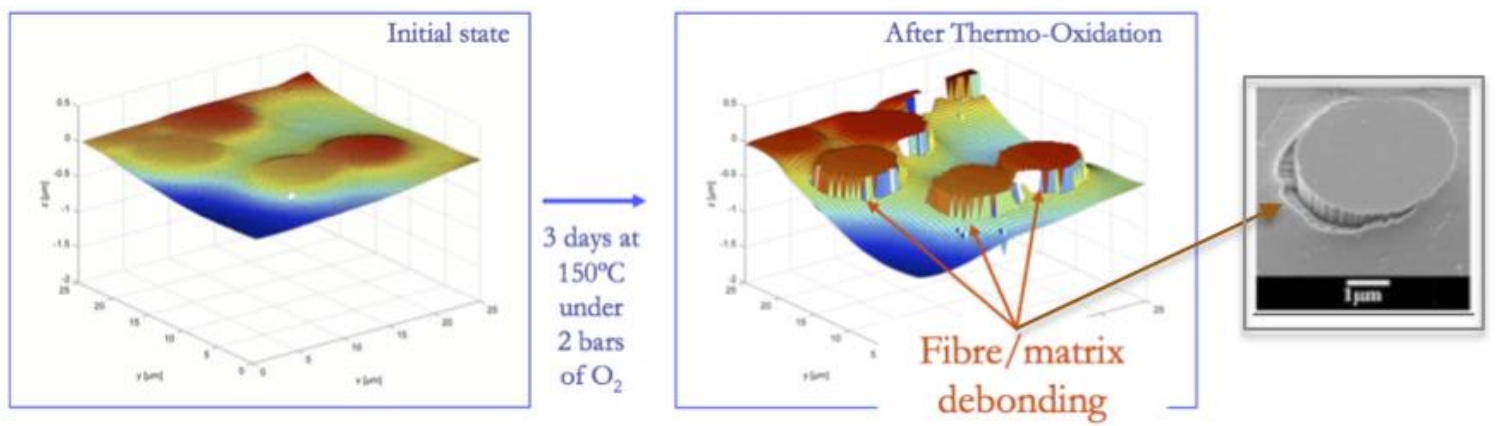

Fig. 6 3D reconstruction by confocal interferometric microscopy and SEM observation of the surface of a virgin and oxidised UD composite sample. Aging conditions: 3 days under 2 bars of oxygen at $150^{\circ} \mathrm{C}$

same thickness than the previous one, forms in turn beyond the crack tip, etc... As a result, cracking propagates by leaps until the complete failure of the sample without the help of an imposed external mechanical loading (Colin et al. 2005).

\subsection{Unidirectional composite ply}

In the unidirectional composite ply (UD), the thermal oxidation results in matrix shrinkage between fibres, which leads to the initiation of damage on the surface in contact with the environment, firstly as fibre/matrix debonding. The shrinkage depth, which is related to the oxidation level of the composite, can be measured using a Confocal Interferometric Microscope (CIM), which also enables us to reconstruct a 3D surface mapping (Fig. 6). The fibre/matrix decohesions can be identified using the "non-measured" points by CIM, which are associated to profiles too steep to be followed by the optical method (Fig. 6 and Fig. 7). During aging, the depth of the matrix shrinkage profiles increases (Fig. 7) and a detailed analysis shows that the maximum 


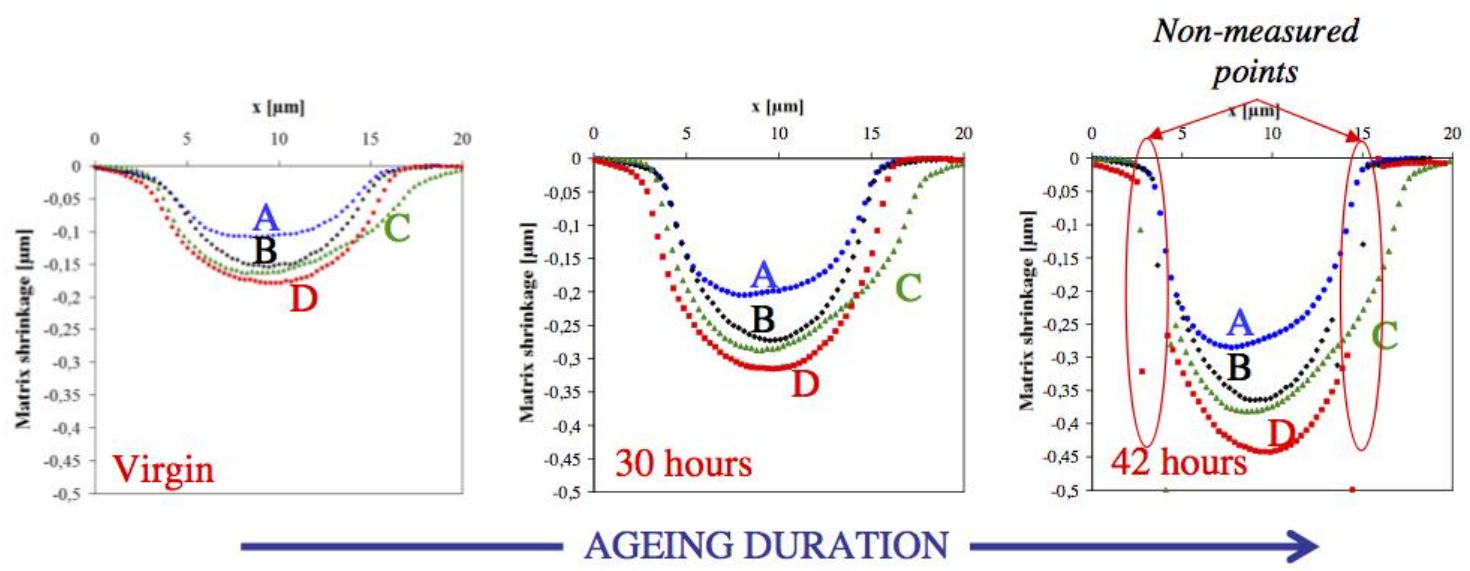

Fig. 7 Matrix shrinkage evolution measured between two fibres distant from 20 micrometres and onset of F/M debonding (non-measured points). Aging conditions: 2 bars of oxygen at $150^{\circ} \mathrm{C}$

shrinkage depth increases as the distance between fibers increases, and is higher in matrix rich zones (low Vf).

\subsection{Laminated composite}

The orientation of the fibres within the composite generates anisotropy in the evolution of the oxidized/degraded zone at the ply's scale. Dark field microscopy observations on polished sections of [0]n and [90/0]s specimens aged in air at $150^{\circ} \mathrm{C}$ (Fig. 8 (a)) display a zone of a lighter colour along the edges of the specimens exposed to the environment. The oxidation along the specimens' edges, indeed, leads to mechanical degradation: the roughness of the oxidized/degraded surface after polishing is different from the one of the unoxidized surface, and this difference is highlighted by the dark field microscopy. For specimens with different aging durations, one can observe that the thickness of this lighter zone increases with time: in particular, the progression from the surface perpendicular to the fibres' direction is much faster than from the surface parallel to the fibres' direction.

The observed anisotropy is mainly related to the fibre/matrix interphase: on one hand, its material properties are generally different from those of the bulk polymer, but they are difficult to characterize directly; on the other hand, it is subjected to high stresses due to the differential shrinkage related to oxidation, thus it constitutes a preferential site for crack creation and propagation and further oxygen diffusion.

For relatively long aging times (here, 6 weeks in air at $150^{\circ} \mathrm{C}$ ), matrix cracks starting from a surface parallel to the fibres' direction were also observed after aging (Fig. 8(b)). Unlike 'classical' matrix cracks, which generally traverse the whole thickness of a ply, these cracks involved only a portion of the external plies, and thus they will be called 'partial cracks' hereafter. The partial cracks develop in the absence of external mechanical loading, and they are driven by two different physical mechanisms, both associated to oxidation: a) the embrittlement of the matrix and of the interphase, which decreases the fracture toughness of the material, b) the gradient of matrix shrinkage, which constitutes the driving force for cracking initiation and propagation. In classical aging tests, in which oxidation occurs without an imposed external mechanical loading, it is not 


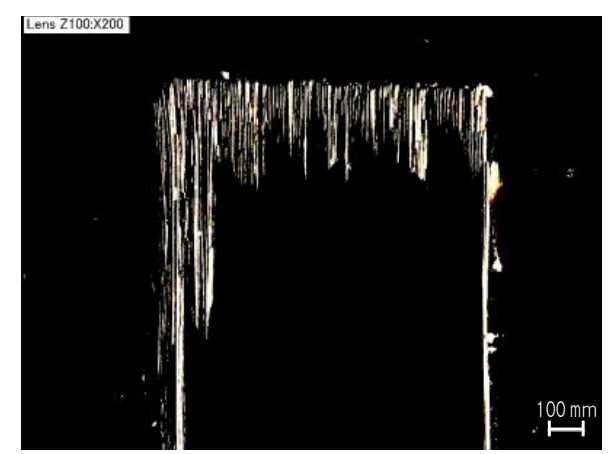

(a) Oxidized/degraded zone under dark field.

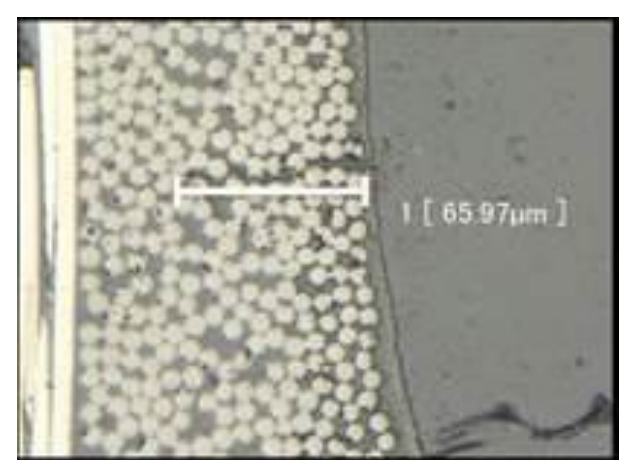

(b) Partial transverse crack under light field.

Fig. 8 Microscopic observations of specimens aged 6 weeks in air at $150^{\circ} \mathrm{C}$

possible to identify these two mechanisms separately. In order to obtain more information on the embrittlement, a new oxi-delamination test is proposed in Section 4.4: in this test, delamination propagation is driven by oxidation in the presence of an external mechanical loading, which is imposed independently.

\section{Controlling parameters}

The oxidation kinetics of the Tactix polymer depends not only on time and temperature, but also on oxygen partial pressure. It is also suspected that oxidation is accelerated by the presence of a mechanical loading. In order to build a kinetic modelling tool predicting the course of oxidation and its consequences on physical and mechanical properties, a specific study on the impact of these different environmental factors is required. This study should be performed on sufficiently thin polymer films (of thickness typically lower than $100 \mu \mathrm{m}$ ) for which oxidation can be considered as homogeneous, i.e., is not limited by oxygen diffusion. In a second step, oxygen diffusion will be coupled with its chemical consumption into the kinetic modelling tool in order to simulate the oxidation profiles in thicker polymer samples.

\subsection{Time or rate}

Several tracers can be used to follow the course of Tactix oxidation in given conditions of temperature and oxygen partial pressure. At molecular scale, two main oxidation products are detected by IR spectrophotometry: carbonyl $(C=\mathrm{O})$ and amide groups $(>N-(C=O)-)$ displaying absorption bands at respectively 1725 and $1680 \mathrm{~cm}^{-1}$ in IR spectra (Fig. 2). The build-up of both groups at $200^{\circ} \mathrm{C}$ in air is shown in Fig. 9, simultaneously with the substrate consumption. The extent of this latter has been evaluated by monitoring the disappearance of oxymethylene groups ($\mathrm{O}-\mathrm{CH}_{2}-$ ) at $1034 \mathrm{~cm}^{-1}$. In Fig. 9, it appears clearly that oxidation starts quasi-instantaneously with a maximal rate. It can be considered that there is no induction period and therefore, the steady-state regime appears from the early period of exposure. When the substrate concentration is reduced of typically $20 \%$, the oxidation rate begins to decrease substantially. This latter presumably vanishes with the substrate concentration. Thenceforth, the concentration of oxidation products reaches a maximal value. 


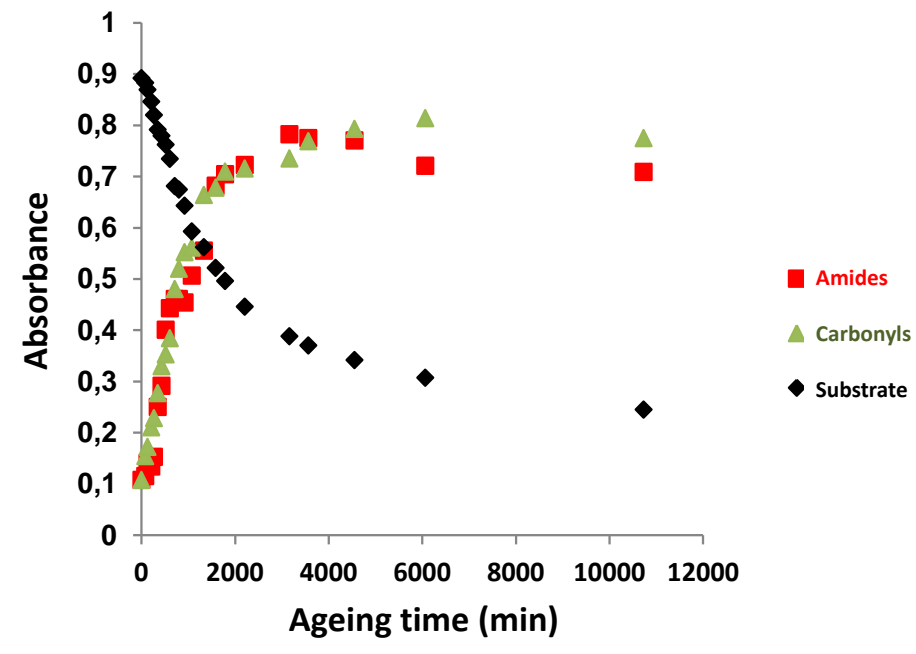

Fig. 9 Changes in the chemical composition of thin Tactix films during their thermal aging. Build-up of oxidation products (carbonyl and amide groups) and consumption of substrate at $200^{\circ} \mathrm{C}$ in air

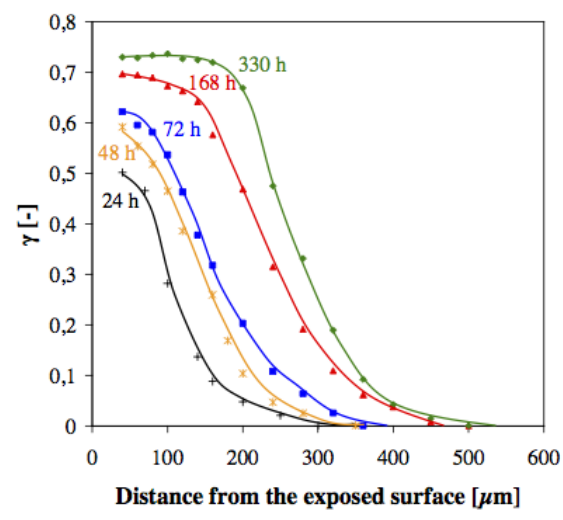

(a) $\gamma$ profiles for Tactix resin specimens

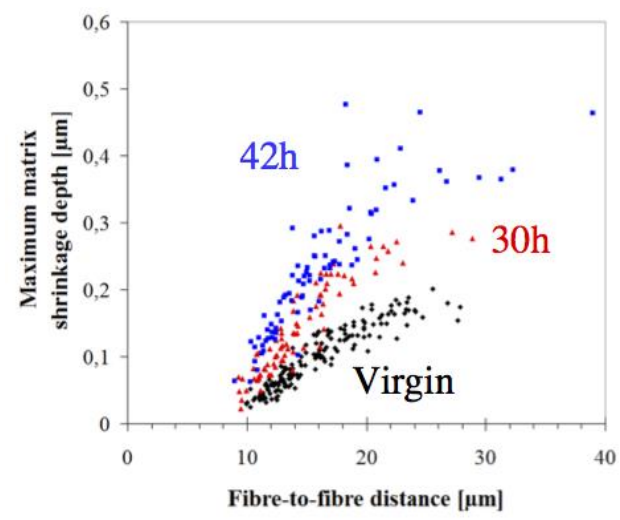

(b) Maximum depth of matrix shrinkage in UD composite as a function of the distance between fibres and oxidation time

Fig. 10 Micro-indentation on aged sample. Aging conditions: 2 bars of oxygen at $150^{\circ} \mathrm{C}$

In a thick polymer specimen, the thermal oxidation leads to the development of an oxidized layer, in which the elastic modulus of indentation increases, due to the antiplasticization phenomenon previously described. In Fig. 10(a), the tracer of oxidation is the parameter $\gamma$, a phenomenological parameter defined from EIT measurements as Eq. (1)

$$
\gamma(T, p, t, z)=\frac{\operatorname{EIT}(T, p, t, z)}{E I T_{0}}
$$

where $T$ is the aging temperature, $p$ the oxygen partial pressure, $t$ the oxidation time, $z$ the distance to the surface area exposed to the environment, and $E I T_{0}$ the indentation modulus of the virgin polymer. In this Fig. 10(a), it is observed that if the oxidation increases at the sample surface in the same manner as in Fig. 9 (no induction period followed by an auto-deceleration), the gradient of 
properties, observed along the sample thickness and induced by the diffusion-reaction coupling, is propagated from the edge towards the specimen core. In addition, the EIT profiles as well as the changes over time of the oxidized layer thickness depend on oxygen diffusion and reaction rate constants that determine the thermal oxidation kinetics.

In the UD composite, the matrix shrinkage profiles deepen with the increase of aging time (Fig. 10(b)) and induces the onset of fibre/matrix debonding, that results in a sudden increase in the values of "shrinkage depth" measured by CIM. According to the local fibre configuration, the time at which this debonding occurs varies.

\subsection{Temperature}

The effect of exposure temperature on the oxidation kinetics of thin Tactix films is reported in Fig. 11(a). Carbonyl groups have been selected as oxidation tracers to illustrate the results. The same conclusions could be obtained with amide groups since both types of oxidation products accumulate simultaneously in the Tactix films (Fig. 9) It appears clearly that, after an induction period during which the effects of oxidation are practically no detectable, oxidation autoaccelerates suddenly to reach a steady-state. The induction time and maximum oxidation rate are respectively decreasing and increasing functions of the temperature between 120 and $200^{\circ} \mathrm{C}$.

It has been checked that oxidation rate obeys an Arrhenius law in this temperature range. A straight-line has been obtained when plotting the logarithm of the maximum oxidation rate as a function of the reciprocal temperature. A corresponding activation energy of about $101 \mathrm{~kJ}^{\mathrm{mol}}{ }^{-1}$ has been calculated from the slope of the straight-line.

\subsection{Oxygen partial pressure}

The effect of oxygen partial pressure on the oxidation kinetics of thin Tactix films has been also assessed between 0.2 bar (corresponding to air) and 20 bars at $150^{\circ} \mathrm{C}$. In Fig. 11, it appears clearly that the oxygen pressure is a second important accelerating factor. Contrarily to temperature, it can be used to accelerate the oxidation kinetics without changing the oxidation mechanism.

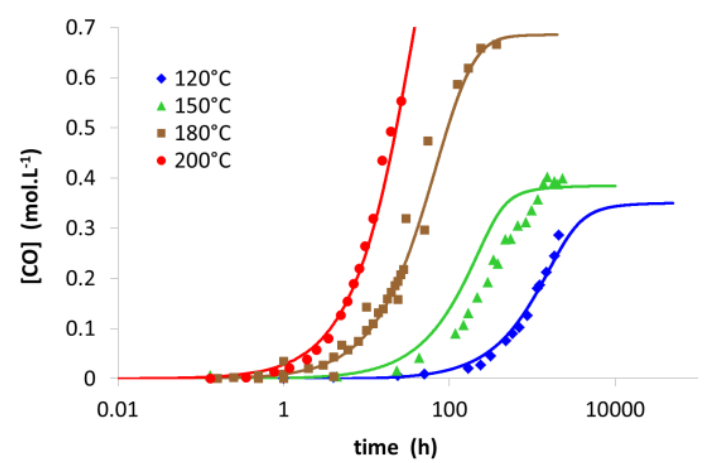

(a) Between 120 and $200^{\circ} \mathrm{C}$ in air

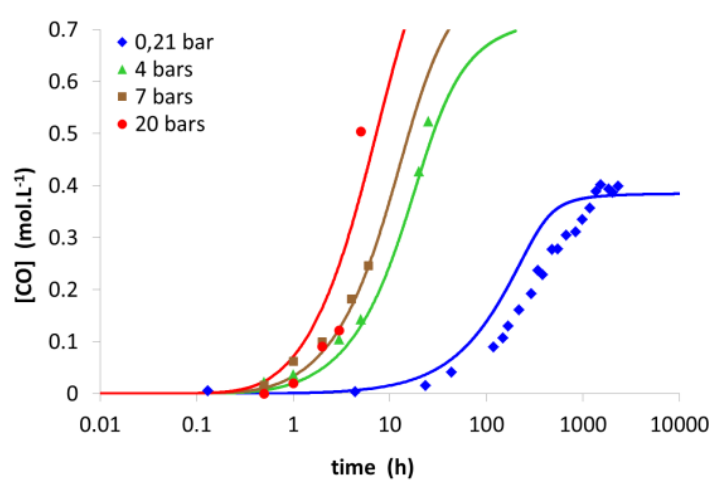

(b) At $150^{\circ} \mathrm{C}$ under different oxygen partial pressures

Fig. 11 Kinetic curves of carbonyl accumulation in thin Tactix films. Symbols correspond to experimental data and solid lines to kinetic modeling 


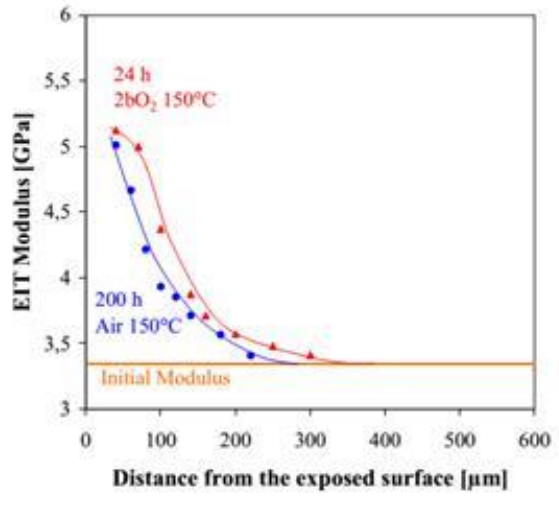

(a) Tactix resin after $24 \mathrm{~h}$ under 2 bars of oxygen and $200 \mathrm{~h}$ in air

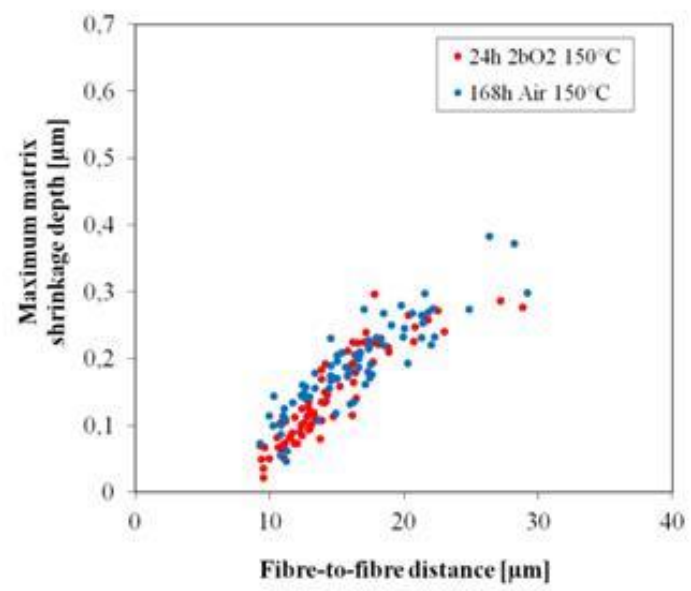

(b) Maximum depth of shrinkage depending on the distance between fibres on the surface of UD composite

Fig. 12 Comparison of $\gamma$ profiles in oxidized layers

Thanks to the kinetic modelling tool (see below), it can be demonstrated that the oxidation rate reaches a maximal value when the oxygen pressure becomes higher than typically 5 bars. In other words, beyond this critical value, oxygen can be considered in excess in the Tactix film. It is noteworthy that $L$. Olivier reported the same value at $150^{\circ} \mathrm{C}$ but for another epoxy-diamine system (referenced as 977-2) in his $\mathrm{PhD}$ thesis (Olivier 2008).

In the polymer as in the UD composite, increasing the oxygen partial pressure accelerates the thermal oxidation process: an oxidized layer of the same thickness and having similar gradient of properties can be obtained for shorter time by increasing moderately the oxygen pressure. For example, for Tactix polymer, an equivalent oxidized layer is measured either after $24 \mathrm{~h}$ of aging under 2 bars of oxygen, or after 200h in air (Fig. 12(a)). Moreover, (Fig 12(b)) shows that the matrix shrinkage measured on the surface of the UD composite exhibits the same distribution for both test conditions. This result suggests the possibility to accelerate thermo-oxidation testing by increasing oxygen partial pressure.

\subsection{Mechanical loading}

The final aim of the COMPTINN' project is to predict the lifetime of composites subjected to combined mechanical and environmental loadings. The influence of the mechanical loading on the evolution of thermo-oxidation must therefore be investigated.

All the experiments discussed in the previous Sections are related to specimens aged in the absence of an external mechanical loading. Due to the oxidation gradients and to the presence of fibres, significant local stresses develop both in polymer and in composite specimens, and they can lead to the creation of cracks (see Section 3). These local stresses, however, are directly related to the oxidation level (via matrix shrinkage and evolution of its mechanical properties). For this reason, they cannot be modified independently in order to study their influence on the thermooxidation. 


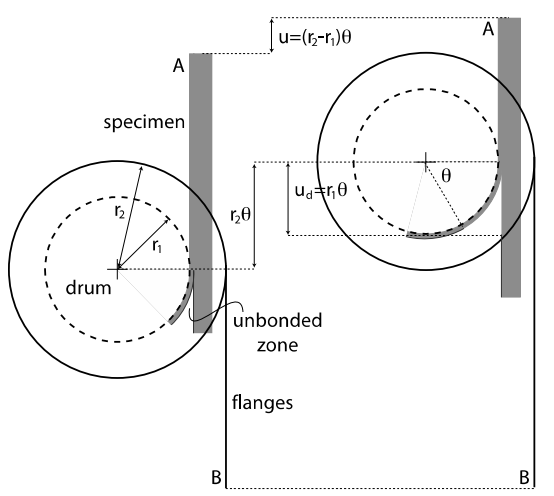

(a) Test setup

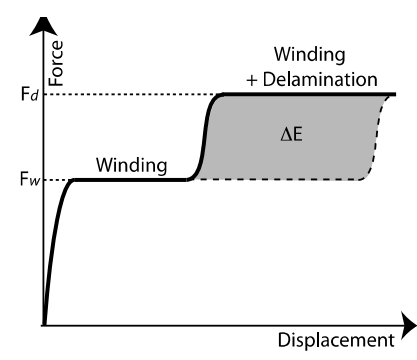

(b) Typical force/displacement curve

Fig. 13 Principle of the CDP test

A new oxi-delamination test was designed and carried out within the COMPTINN' project in order to study the coupling between oxidation and mechanical loading (Daghia and Cluzel 2013) and (Daghia and Cluzel 2014). In this test, the propagation of delamination is driven by oxidation, in the presence of an external imposed mechanical loading. Some preliminary results obtained on a different carbon/epoxy system are illustrated in the following.

\section{The oxi-delamination test}

The oxi-delamination test is based on the Climbing Drum Peel Test (ASTM D1781). Standard test method for climbing drum peel for adhesives. The CDP test is classically used to determine the mode I fracture toughness of the skin-core bonding in sandwich composites (Nettles et al 2007). Here, it was modified in order to determine the oxidized fracture toughness of a monolithic composite specimen.

The principle of the CDP test is shown in Fig. 13(a). An initial pre-crack divides the specimen into two parts of different thickness: a thin, flexible part and a thick, stiff part. The flexible part is wound around a drum with a constant radius, which causes propagation of the delamination. In a typical CDP test, an increasing displacement is imposed between points $A$ and $B$ and two loading portions are observed with constant force (Fig. 13(b)): $F w$ corresponds to the force required to lift the drum and to wind the pre-delaminated part of the specimen around the drum, while in $F d$ the force required for the propagation of the delamination is also included. The critical strain energy release rate can thus be determined only by knowing $(F d-F w)$ and the geometry of the drum and the specimen.

In the modified version of the test proposed here, a constant force Fext so that $F w<F e x t<F d$ is imposed on the specimen, which is then placed in an oxidizing environment. Since the available rate of energy Gext is lower than the one needed for propagation in a healthy material GIc,s, the degradation of the fracture toughness due to oxidation is responsible for the propagation (that is, during propagation one has GIc,ox=Gext). The velocity of the crack propagation is measured for different levels of Gext (see Fig. 14). Thanks to a diffusion/reaction model, it is then possible to link the inverse of the crack propagation velocity to the oxidation level, and thus to identify their relation (see Fig. 15).

Fig. 14(a) shows the raw displacement measurements obtained during the tests. In particular, the nearly flat portions of the curves correspond to the periods during which the external applied 
load was kept constant, while the displacement jumps correspond to the sudden load increases. In Fig. 14(b), these displacement jumps have been removed and the drum geometry has been used to transform the displacement $u$ (between the top and the bottom of the specimen) into the displacement $u d$ (between the drum and the specimen), which corresponds to the propagation of the delamination (see scheme in Fig. 13(a)). As it can be seen, the displacements measured during the constant loading phases are very small with respect to the global displacements occurring during the test. The order of magnitude of the microns per hour for the crack propagation velocity, which could be expected from the spontaneous cracking observed during aging, is confirmed here. Obtaining precise enough measures of the crack propagation velocities is a challenge of the oxidelamination test.

Furthermore, a significant transient phase was observed, and the crack propagation velocities appear to be influenced by the loading history. It is possible that, at high temperature, a local viscous mechanism appears in addition to the diffusion/reaction/cracking mechanisms considered up to now. Although this additional mechanism significantly complicates the post-treatment of the oxi-delamination test data, this test appears to be an interesting tool to differentiate the various physical phenomena occurring in oxidized specimens, since it enables us to modify independently the different loading parameters (mechanical loading, temperature, oxygen partial pressure).

\section{Multiphysics coupled modelling}

The objective in this section is to give an overview of the various modelling tools developed within the COMPTINN' program to predict the thermo-oxidation behaviour of HTS-TACTIX carbon-epoxy composite at 'high' temperatures $\left(120^{\circ} \mathrm{C}-180^{\circ} \mathrm{C}\right)$. First of all, a kinetic modelling tool has been derived from the thermal oxidation mechanism of the Tactix polymer. This tool is able to describe all the experimental features of the thermal oxidation kinetics reported in previous sections, in particular the dependencies of the kinetic curves of oxidation product accumulation with temperature and oxygen partial pressure. Since it couples oxygen diffusion and its chemical consumption into a balance equation, it is also able to simulate the formation of the thickness profiles of chemical events into thick samples, in particular the development of the superficial oxidized layer (Fig. 5). In the case of oxygen diffusion in a single direction (the sample thickness), this balance equation writes Eq. (2)

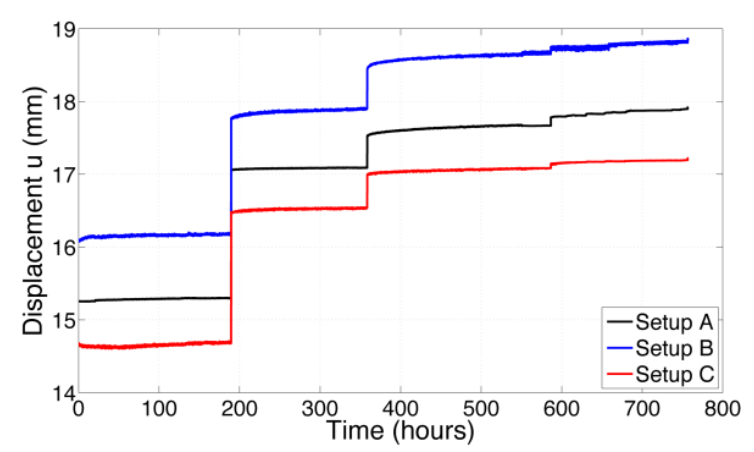

(a) Raw measurements

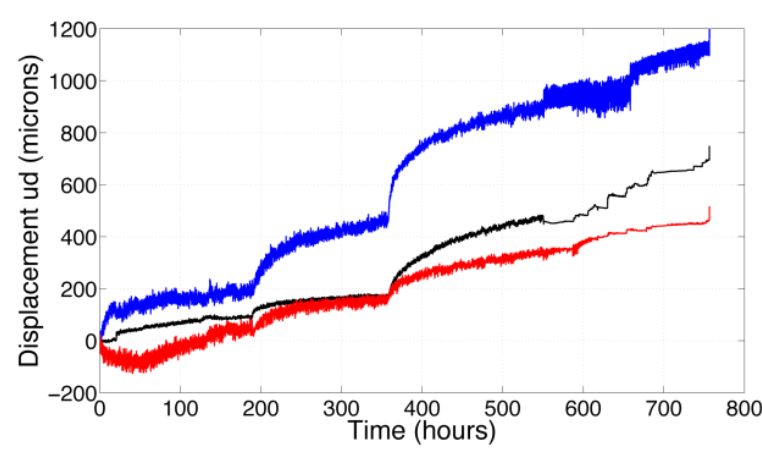

(b) Post-treatment of the constant stress portions

Fig. 14 Measured displacements for 40, 44, 48 and $49 \mathrm{~N}$ imposed forces 


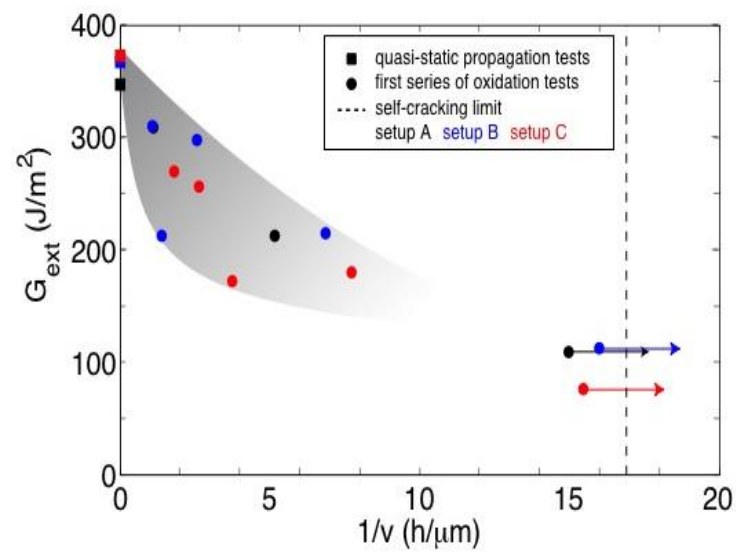

Fig. 15 Imposed strain energy release rate versus inverse of the crack propagation velocity for the oxi-delamination tests

$$
\frac{d\left[\mathrm{O}_{2}\right]}{d t}=D \frac{\partial^{2}\left[\mathrm{O}_{2}\right]}{\partial z^{2}}-r\left(\left[\mathrm{O}_{2}\right]\right)
$$

where $D$ is the coefficient of oxygen diffusion into the polymer, $r\left(\left[\mathrm{O}_{2}\right]\right)$ is the local rate of oxygen chemical consumption, $t$ is the exposure time and $z$ is the depth beneath the sample surface.

Finally, the kinetic modelling tool has been interfaced with structure/property relationships or more sophisticated mechanical tools in order to predict the consequences of thermal oxidation on physical and mechanical properties.

In particular, a constitutive model describing the matrix behaviour as a function of a given oxidation indicator has been developed. This model has enabled us to characterize and predict the differential shrinkage occurring within the composite at the fibre's scale. The description of the effect of oxidation on the laminated composite requires further upscaling of the discussed effects towards the scale of the ply. The kinetic modelling tool, the constitutive model and homogenization techniques constitute an entry point for modelling at the ply's scale. We can then account for the development of partial transverse cracks in the composite during aging and for the interaction between aging and mechanical loading on the determination of the kinetic of transverse cracking.

\subsection{Reaction-diffusion modelling and oxidized layer interpretation}

At temperatures lower than typically $200^{\circ} \mathrm{C}$, the thermal oxidation mechanism of the Tactix polymer can be summarized by the three following stages:

$$
\begin{aligned}
& \text { Initiation: } \quad \text { Hydroperoxydes } \rightarrow \text { Radicals }+ \text { Oxidation products }+ \text { Chain scissions }\left(k_{1}\right) \\
& \text { Propagation: Radical }+\mathrm{O}_{2} \quad \rightarrow \text { Radical } \quad\left(k_{2}\right) \\
& \text { Radical }+ \text { Substrate } \rightarrow \text { Hydroperoxyde }+ \text { Radical } \\
& \text { Terminations: Radical } \left.+ \text { Radical } \rightarrow \text { Oxidation products }+ \text { Crosslinks }+\mathrm{O}_{2} \quad \text { (k4to } k_{6}\right)
\end{aligned}
$$

where $k_{i}$ are the rate constants of the different elementary steps. Obviously, they only depend on 
the temperature according to an Arrhenius law.

In this case, the initiation step consists in the thermal decomposition of the most unstable chemical species, which are also the main propagation products: hydroperoxydes ( $\mathrm{POOH})$. The alkyl radicals $\left(P^{\circ}\right)$ resulting from the hydroperoxyde decomposition propagate oxidation by reacting with the oxygen dissolved into the polymer matrix (to form peroxy radicals $\mathrm{PO}_{2}{ }^{\circ}$ ), then by abstracting labile hydrogen atoms from the substrate $(\mathrm{PH})$. Both types of radicals $\left(\mathrm{P}^{\circ}\right.$ and $\left.\mathrm{PO}_{2}{ }^{\circ}\right)$ can terminate according to bimolecular reactions.

From this mechanism, a kinetic modelling tool has been derived using the classical concepts of chemical kinetics. It consists in a system of 5 non-linear differential equations quantifying the chemical modifications of the Tactix polymer in every elemental layer of the sample thickness. Let us remember that the changes in oxygen concentration are described by Eq. (2), the local rate of oxygen chemical consumption being given by Eq. (3)

$$
r\left(\left[\mathrm{O}_{2}\right]\right)=k_{2}\left[\mathrm{O}_{2}\right]\left[\mathrm{P}^{\circ}\right]-k_{6}\left[\mathrm{PO}_{2}^{\circ}\right]^{2}
$$

To get a good idea on this kind of approach, the reader can consult the reference (Colin and Verdu 2005).

This system has been solved simultaneously in time $(t)$ and space $(z)$ using the recommended numerical algorithms for stiff problems of chemical kinetics, in particular the ODE23s solver of Matlab commercial software (Hairer and Wanner 1996). Its resolution has given access to the thickness distribution of the concentrations of reactive species (i.e., $\mathrm{P}^{\circ}, \mathrm{PO}_{2}^{\circ}, \mathrm{POOH}, \mathrm{PH}$ and $\mathrm{O}_{2}$ ), but also their changes against time of exposure. The concentration profiles of oxidation products (in particular carbonyl groups $C=O$ ) and macromolecular modifications (chain scissions s and crosslinks $x$ ) have been then calculated in the post-treatment stage with the following differential equations Eqs. (4)-(5)-(6)

$$
\begin{gathered}
\frac{d[\mathrm{CO}]}{d t}=\gamma_{C O} k_{1}[\mathrm{POOH}]^{\delta} \\
\frac{d s}{d t}=\gamma_{1} k_{1}[\mathrm{POOH}]^{\delta} \\
\frac{d x}{d t}=\gamma_{4} k_{4}\left[P^{\circ}\right]^{2}+\gamma_{5} k_{5}\left[P^{\circ}\right]\left[\mathrm{PO}_{2}^{\circ}\right]+\gamma_{6} k_{6}\left[\mathrm{PO}_{2}^{\circ}\right]^{2}
\end{gathered}
$$

where $\delta$ is the molecularity of the hydroperoxyde decomposition. $\delta=1$ for an unimolecular decomposition, whereas $\delta=2$ for a bimolecular one.

$\gamma_{C O}$ and $\gamma_{1}$ are the respective formation yields of carbonyl groups and chain scissions in the initiation stage. $\gamma_{4}, \gamma_{5}$ and $\gamma_{6}$ are the respective formation yields of crosslinks in the different termination steps.

To check the validity of the kinetic model, the accumulation curves of carbonyl groups have been simulated for different temperatures (typically between 120 and $200^{\circ} \mathrm{C}$ ) and oxygen partial pressures (between 0.2 and 20 bar) and compared to experimental data. Fig. 10 demonstrates the good predictive value of the kinetic model. It can be thus concluded that this latter describes accurately the acceleration of the oxidation kinetics by increasing the oxygen partial pressure and temperature. This result indicates that the mathematical expressions (Eq. (2) and Eq. (3)) proposed for establishing the oxygen balance into the material are quite realistic and present a real physical meaning, but also that the Arrhenius laws of all elementary parameters (i.e., coefficient of oxygen diffusion and rate constants) has been correctly adjusted by inverse resolution method.

In the case of epoxy-diamine networks, chain scissions are largely predominant over 
crosslinking. It is suspected that they preferentially involve the oxymethylene groups of hydroxypropylether segments, whose $\beta$ motions are responsible for the high temperature side of the $\beta$ dissipation band in DMA spectra. As a result, they decrease catastrophically the glass transition temperature, but also they increase significantly the storage modulus at glassy plateau between $T \beta$ and $T \alpha$ (Fig. 4(a)). This phenomenon is called "internal antiplasticization" (Minervino et al. 2008). Starting from these observations, the Di Marzio and Gilbert's theories have been successfully used to establish relationships between the glass transition temperature and number of chain scissions, and between the storage modulus and $\beta$ transition activity respectively (Terekhina et al. 2013, within COMPTINN).

\subsection{Constitutive law of oxidised epoxy resin and structural effect}

Previous studies have established a phenomenological correlation between the indentation elastic modulus (EIT, a mechanical property of the material) and the total concentration of the oxidation products $(Q$, an indicator of the progress of the chemical reaction of oxidation) (Olivier et al. 2008): the existence of such a correlation is not without consequences, as it identifies the elastic indentation modulus, or the phenomenological parameter of aging, $\gamma$, as a tracer of the chemical reaction. In this study, the validity of this choice is supported by the observation that a same value of $\gamma$ corresponds always to a same indentation curve 'load vs penetration depth' and thus to a same local mechanical behaviour (Fig. 16). This has been verified for several "aging time $\mathrm{t}$ - edge distance $z$ " couples and several values of the oxygen partial pressure.

Such a correlation can be kinetically justified only if the oxidation products, chosen as an oxidation tracer at the molar scale, result essentially from a chain scission process. For instance, this is the case for carbonyl groups (see Eqs. (4) and (5)).

The fact that the same value of $\gamma$ always matches the same indentation curve, regardless the

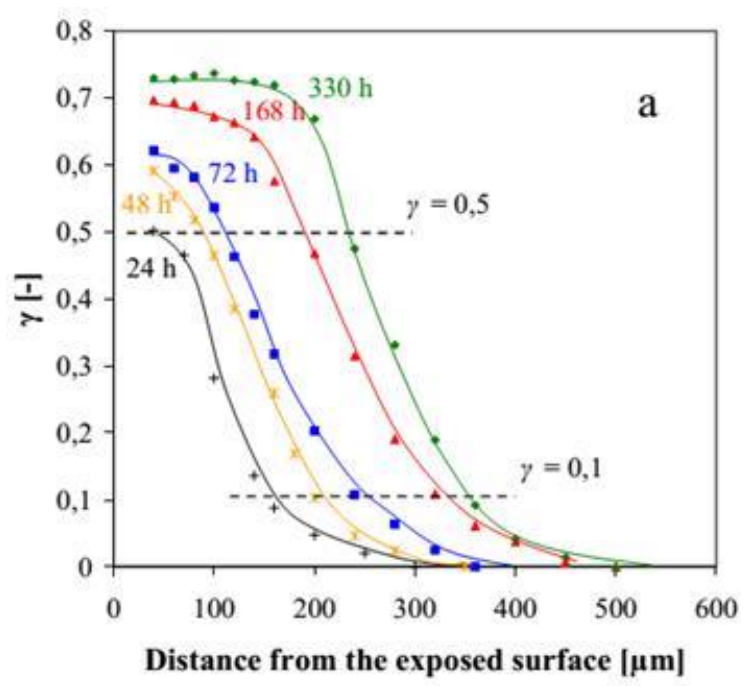

(a) $\gamma$ profiles as function of distance from the specimen edge for several aging times

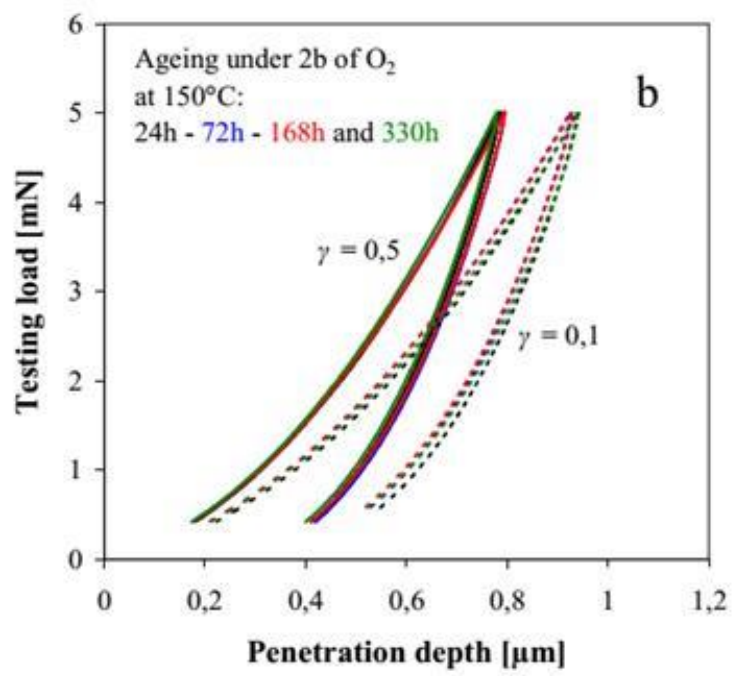

(b) Comparison of indentation curves for two values of $\gamma$

Fig. 16 Micro indentation on aged sample. Aging conditions: 2 bars of oxygen at $150^{\circ} \mathrm{C}$ 


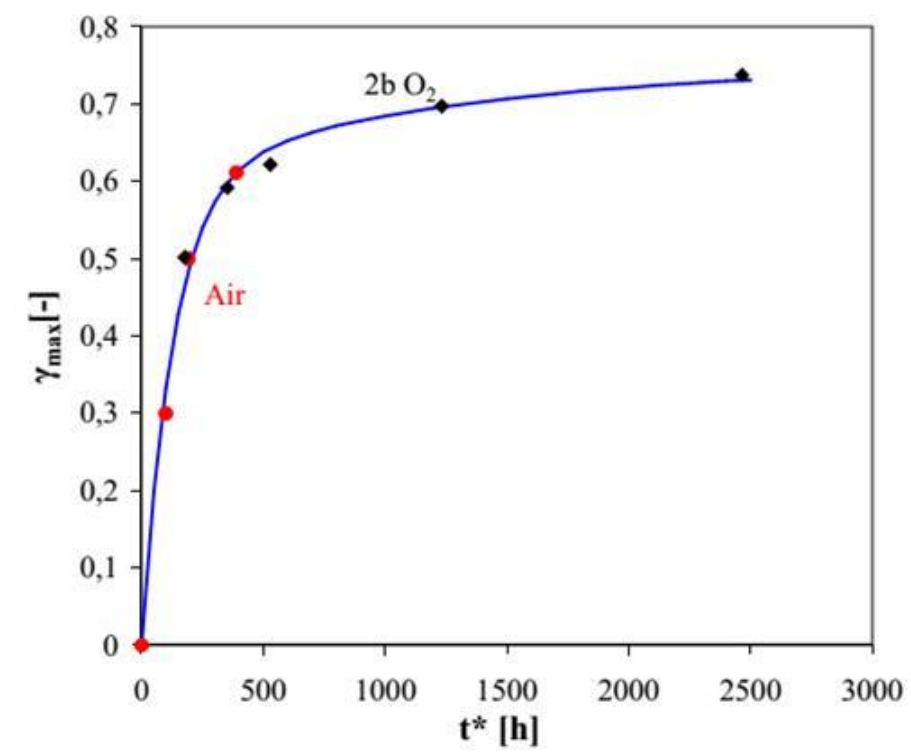

Fig. 17 Thermal aging 'master curve' of $\gamma$ max as function of a reduced aging time for Tactix at $150^{\circ} \mathrm{C}$. Symbols correspond to experimental data and solid lines to modelling

history of aging (time, space and pressure), has two important consequences:

- a direct link can be established between the local mechanical behaviour of the polymer and the phenomenological aging parameter $\gamma$. In other words, the construction of a constitutive law of the oxidized thermo-set resin as a function of $\gamma$ is relevant.

- the oxygen partial pressure is a valid method of acceleration.

With this approach, the experimental values of $\gamma_{\max }$, that is the maximum value of $\gamma$ measured closer to the edge of the sample exposed to the environment, are plotted in Fig. 17 as a function of a reduced aging time. This one is defined as the period of aging times a $\lambda$ 'shift factor' (found equal to 7 between 2 bars of $\mathrm{O}_{2}$ and 1 bar of air for TACTIX resin aged at $T=150^{\circ} \mathrm{C}$ ). Thus, we can construct a "master curve" which shows the equivalence time-pressure and predicts, for example, the value of $\gamma_{\max }$ reached after a $2500 \mathrm{~h}$ thermal aging in air without the need to perform this test.

\section{Development of a constitutive law for the oxidised polymer}

The constitutive law of the oxidised resin depending on $\gamma$ and including oxidation-mechanics coupling can be defined starting by a phenomenological thermodynamic potential, $\psi$, given by Eq. (7)

$$
\begin{gathered}
\rho \psi=\frac{3}{2} K_{\infty} \gamma^{*}(\operatorname{tr} E)^{2}+3 K_{\infty} \gamma^{*}\left(\operatorname{tr} E^{T}\right)(\operatorname{trE})+3 K_{\infty} \gamma^{*}\left(\operatorname{tr} E^{C h}(\gamma)\right)(\operatorname{trE})+G_{\infty} \gamma^{*}(\mathrm{Ed}: \mathrm{Ed}) \\
+\frac{3}{2} \sum_{j=1}^{n} K_{j} \gamma^{*}\left(Z^{\operatorname{tr} E j}-Z_{\infty}^{t r E j}\right)^{2}+\sum_{j=1}^{n} G_{j} \gamma^{*}\left(Z^{E d j}-Z_{\infty}^{E d j}\right)^{2}
\end{gathered}
$$

in which $\operatorname{tr} E^{T}=3 \alpha_{T} * \Delta T, \alpha_{T}$ is the thermal expansion coefficient of the resin, $\Delta T$ is the difference between a reference temperature (stress free temperature, often taken as the manufacturing temperature) and room temperature, $\operatorname{tr} E^{C h}(\gamma)$ is the trace of thermo-oxidation induced chemical strain, depending on $\gamma, K_{\infty} \gamma^{*}, G_{\infty} \gamma^{*}, K_{j} \gamma^{*}$ et $G_{j} \gamma^{*}$ are material parameters describing the 

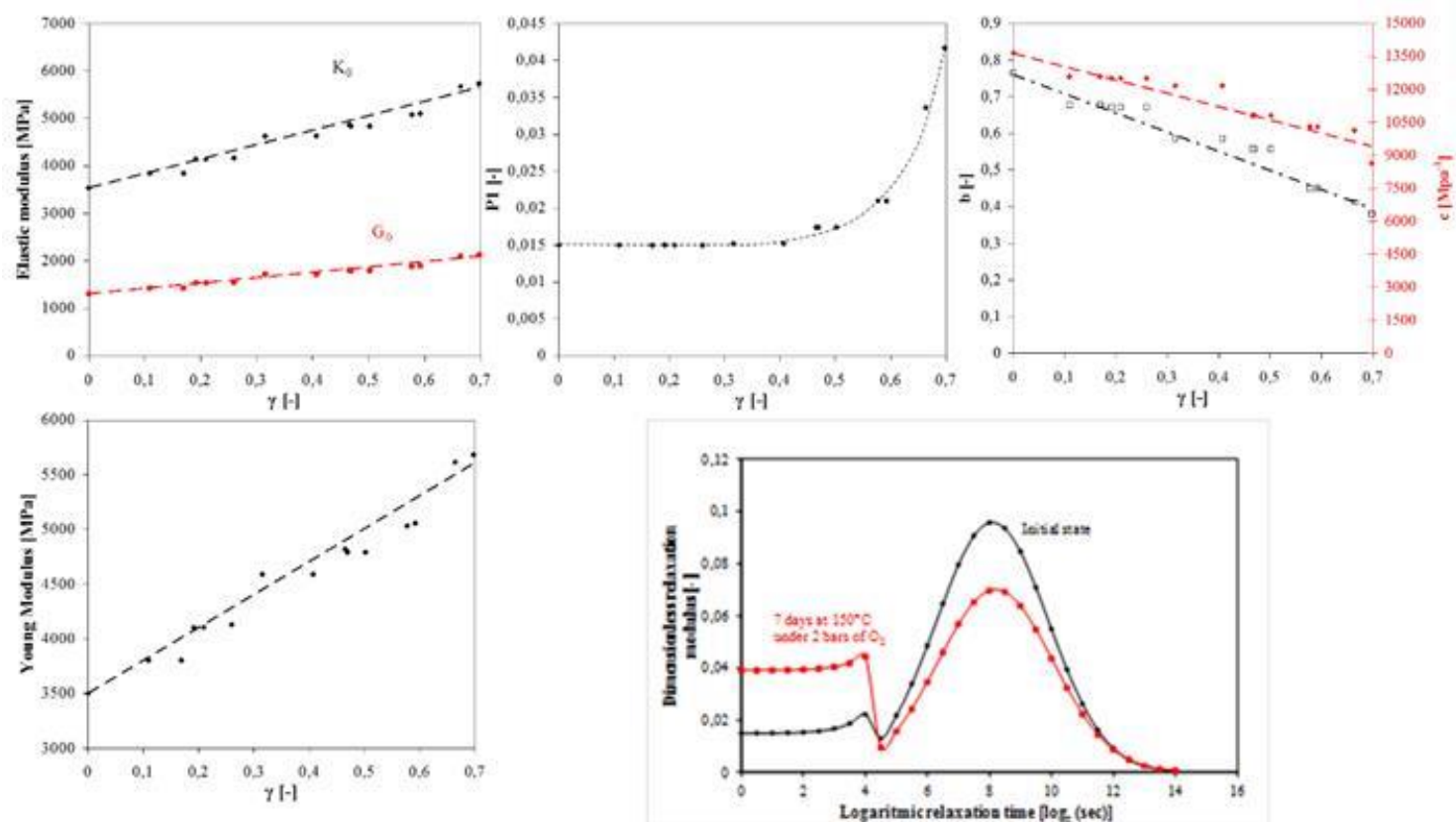

Fig. 18 Evolution of the parameters of the behaviour constitutive law of the oxidized Tactix polymer as a function of $\gamma$. Aging conditions: 2 bars of oxygen at $150^{\circ} \mathrm{C}$

elastic/viscoelastic behaviour of the polymer material, also depending on $\gamma$. The state laws can be found starting by deriving $\psi$, with respect to the state variables. Full detail of the developed constitutive law (not depending on $\gamma$, thus valid for the virgin polymer) can be found in references (Gigliotti et al. 2011) and (Minervino et al. 2015). The identification of the parameters (a total number of 8 parameters, $K_{0}$ and $G_{0}$, for the elastic behaviour, $b$ and $c$ for the softening behaviour and 4 parameters, from $P_{1}$ to $P_{4}$, for the viscoelastic behaviour) is carried out for each polymer sample subjected to the thermo-oxidative aging at $150^{\circ} \mathrm{C}$ under $2 b O_{2}$ for several durations from 1 day to 7 days: this procedure allows identifying a different parameters set for each value of $\gamma$ (Fig. 18). Low scatter of results indicates the robustness of the optimisation procedure and the pertinence of the chosen constitutive law.

From this Fig. 18, it can be concluded that the thermal oxidation results in a more rigid material (according to the results of DMA tests), a less softening behaviour, and with a relaxation spectrum that is redistributed so as to favour the short relaxation times.

\section{Structural effect}

In a sample of neat resin, the oxidized layer is accompanied by chemical deformation, which explains differences in optical contrast observed by white light optical microscopy (Fig. 3(b)), and later, onset of cracking at the surface (Fig. 5).

These effects are even more noticeable in composites (UD or laminated): in this case the resin is "constrained" by the presence of rigid fibres and any expansion is prevented, neither thermal nor chemical. The development of matrix shrinkage between fibres in the composite is therefore a "structural" effect, directly associated with the configuration of the fibres and their local volume fraction. 


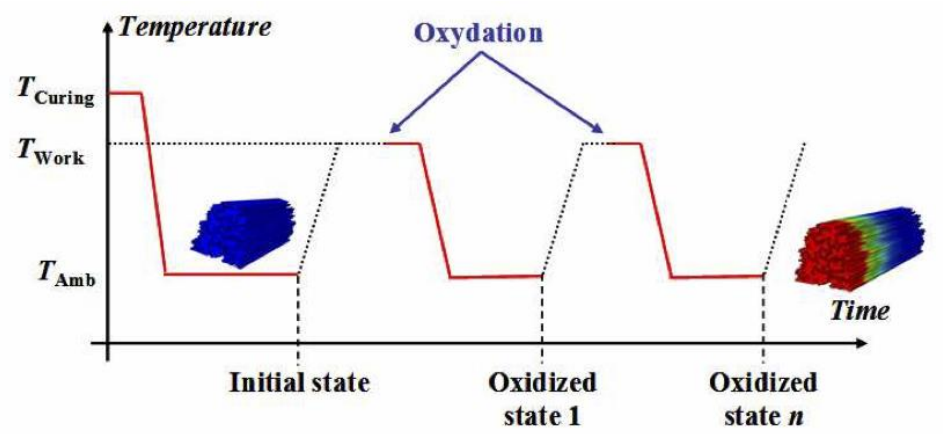

Fig. 19 Thermal history imposed to FEM simulation; Note the gradient of colours depicting the oxidation gradient ( $\gamma$ values)

Numerical modelling of a real microstructure of a UD composite was realized in Abaqus from a representative picture of the surface obtained by MCI. The surface thus obtained was perforated in correspondence with the fibres, and extruded on a depth of 500 micrometres, larger than the maximum size of the oxide layer experimentally measured. The final geometry, three-dimensional, was meshed with 262,000 linear elements with reduced integration (type C3D8R). According to $\mathrm{Vu}$ et al. (2012), matrix shrinkage observable at room temperature on the surface of UD composite is mainly due to the development of irreversible anelastic deformations of the matrix, including thermal strain, $E^{T}$, and chemical strain induced by oxidation, $\mathrm{E}^{\mathrm{Ch}}(\gamma)$.

Since the local mechanical properties of the matrix have been identified, the only unknown of the thermodynamic potential of the matrix are the values of these chemical deformations. For different conditions of thermo-oxidation, numerical simulations have been carried out and the values of the chemical deformations have been obtained by minimizing the differences between matrix shrinkage depth fields measured by CIM and those obtained by numerical simulation. The different steps of the thermal loading imposed for the numerical simulation are shown in Fig. 19.

At each oxidation state of the experimental study is assigned a numerical calculation simulating the corresponding thermo-mechanical loading. The mechanical properties of the matrix and their gradient in the oxide layer are introduced as a function of the single oxidation parameter $\gamma$. A Python script evaluates all along the oxidation time, the appropriate $\gamma$ values to impose at each grid node, according to the distance to the surface exposed to the environment and to aging conditions. It is assumed that $\varepsilon^{\mathrm{Ch}}(\gamma)$ has the same spatial gradient that $\gamma(\mathrm{Eq}$. (8))

$$
\varepsilon^{C h}(\gamma)=\varepsilon_{\text {max }}^{C h}\left(t_{a g}\right) \gamma(t, z)
$$

where $\varepsilon_{\text {max }}^{C h}(t)$ corresponds to the maximum chemical strain at the surface of the specimen, only depending of the thermal aging duration, for a temperature and an oxygen partial pressure prescribed.

Thereafter, the polymer constitutive law (depending on $\gamma$ ) is introduced in Abaqus and the values of $\varepsilon^{C h}{ }_{\max }(t)$ are evaluated thanks to an inverse method associated to an optimisation algorithm. For each stage of thermal aging, the knowledge of this particular maximum chemical deformation provides all shrinkage depth values on the surface of a real composite microstructure. In Fig. 20, some results obtained by this experimental/numerical approach are given. In Fig. 20(a), a shrinkage map obtained by Confocal Interferometric Microscopy (CIM) is shown, and four specific configurations are highlighted: the configurations A, B, C, and D, are characterised by the 


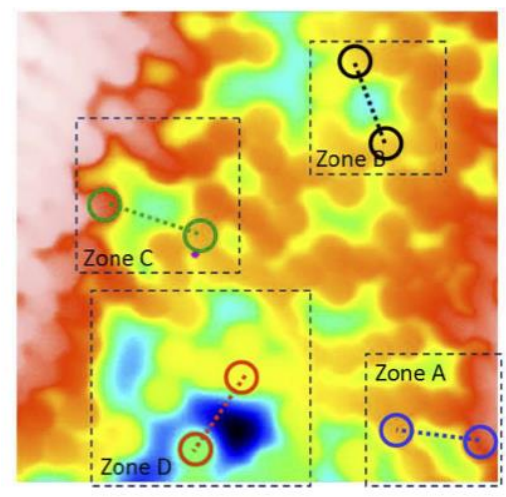

(a) CIM picture of the composite surface

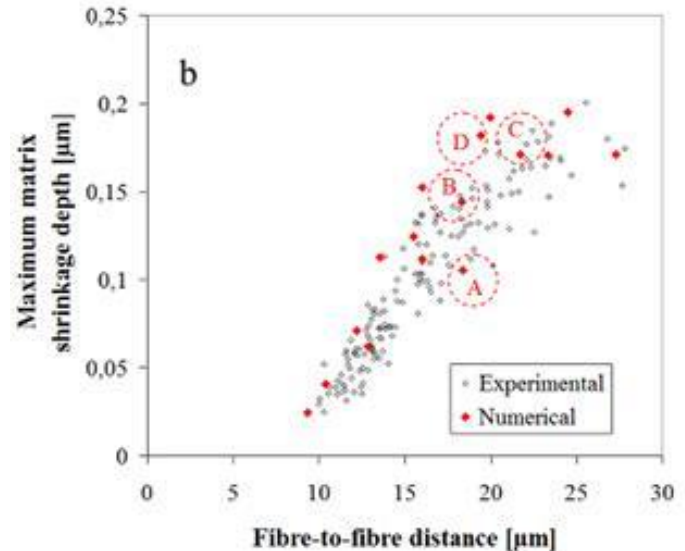

(b) Comparison of experimental and numerical data according to the distance between fibres

Fig. 20 Structural effect in oxidised UD composite visualized by the measurement of shrinkage depths

same distance between fibres $(20 \mu \mathrm{m})$ but in areas presenting different volume fibre ratios. In Fig. 20(b), light grey open symbols visualize the experimental measures of shrinkage depths, whereas the full red symbols correspond to the results of the FEM calculations. The particular values obtained for the configurations $\mathrm{A}, \mathrm{B}, \mathrm{C}$, and D are encircled in order to point out the important role of the local structure configuration on the experimental 'scattering' of the measurements.

\subsection{Towards a mesoscale model}

The prediction of the lifetime of a composite structure under combined mechanical and environmental loading requires accounting for thermo-oxidation in structural scale simulations. In order to do this, mesoscale models such as the one proposed at the LMT Laboratory (see Lubineau and Ladeveze 2008 and Ladeveze et al. 2014 for its enhanced version) should be improved to account for the phenomena associated to thermo-oxidation. The LMT mesomodel describes the ply and the interface between plies as continuous media, and it takes into account phenomena occurring at lower scales via a micro-meso bridge (Ladeveze and Lubineau 2001, Ladeveze and Lubineau 2002). A previous, interesting attempt to account for oxidation-related phenomena via a computational micromodel was discussed in (Lubineau et al. 2009).

The first step towards a mesoscale description is to evaluate the effect of the evolution of the polymer's properties due to oxidation on the ply's material properties. This was carried out by periodic homogenization. A difficult point from the point of view of mesoscale modelling is to affect these modified properties to the oxidized zone, which is generally thinner than a ply: a way to account for this is to separate the ply mesoconstituent in two zones, a healthy and an oxidized zone.

The coupling between mechanical loading and thermo-oxidation remains a critical point of the approach. The oxi-delamination test which was proposed here gives some indications on the evolution of the mesoscopic critical strain energy release rate as a function of the oxidation level. These preliminary results, however, require further studies in order to be properly used, since other mechanisms, and in particular history effects, appear to play a significant role during the test. 


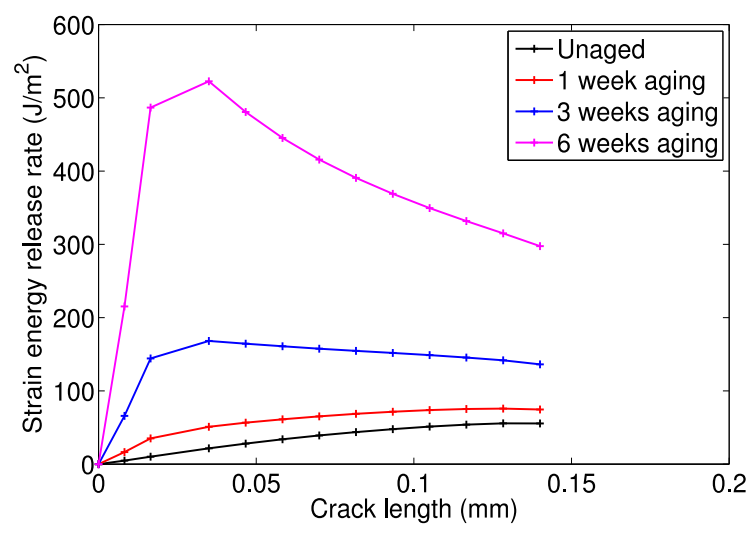

(a) Strain energy release rate as a function of crack length for different aging durations (oxidation and thermal loading, $T=20^{\circ} \mathrm{C}$ )

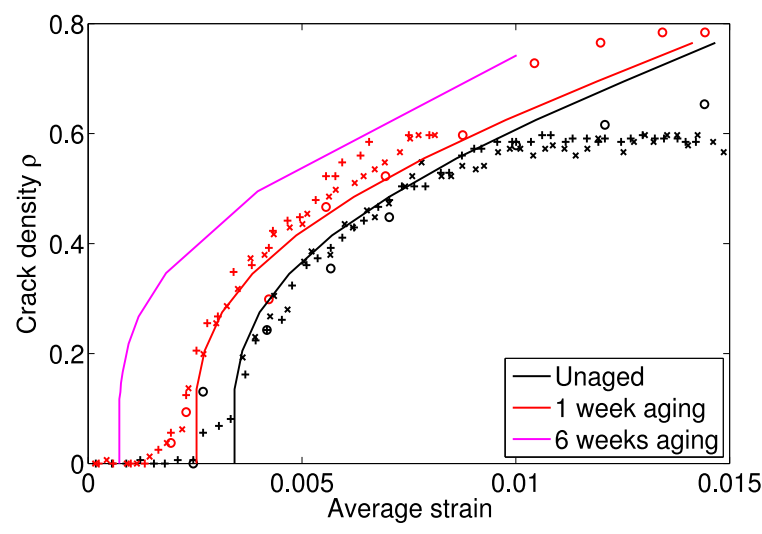

(b) Kinetic of transverse through-ply crack during tensile loadings: experimental (dots) and simulated (lines)

Fig. 21 Crack testing

A first contribution towards the modelling of the behaviour of oxidized specimens under an applied mechanical loading is discussed in a recent paper (Daghia et al. 2015) and it is summarized in the following. It deals with the competition between partial cracks generated during oxidation (Fig. 8(b)) and the transverse cracking observed during mechanical loading.

\section{Kinetics of transverse cracking of aged specimens}

In this study, the [90/0]s specimens discussed in Section 3.3 were aged and then subjected to tensile tests. Digital image correlation was used to measure the kinetic of transverse cracking for the different specimens (for specimens with longer aging durations, both partial and through-ply cracks coexist, thus the kinetic of through-ply cracks could not be easily determined).

The appearance of partial cracks during aging, as well as the cracking kinetics of aged specimens, was simulated via finite fracture mechanics. A finite element model was built, in which the oxidized zone is accounted for in a simplified manner by a model with two layers, and the strain energy release rate was calculated for different cracking configurations. Fig. 21(a) shows the evolution of the strain energy release rate with the crack length for different aging durations: while for short aging durations the crack propagation across the ply is unstable (thus, through-ply cracks are energetically favoured), for longer aging durations partial cracks become advantageous and they can appear even in the absence of external mechanical loading, since the computed strain energy release rate is higher than the critical values typically associated to matrix cracking. Fig. 21(b) shows the influence of the oxidation on the experimental and simulated kinetic of throughply transverse cracking. For specimens aged for 0 and 1 week, both experimental (dots) and simulation (lines) results could be obtained, and a good agreement between the two is observed. For specimens aged 6 weeks, partial and through-ply cracks coexist. Since the two types of cracks could not easily be distinguished in the experiments, no experimental cracking kinetic was determined here. The simulation, on the other hand, enabled us to account for the competition between the two cracking scenarios and to predict the pink curve in Fig. 21(b). Further experimental work is needed to validate this result. 


\section{Conclusions}

In this paragraph, we propose a synthesis of progress made on the understanding and modelling of phenomena associated to thermo-oxidation of carbon fibres/thermoset matrix composites.

Oxygen diffusion in the material and chemical reaction with the polymer are well understood and modelled: the diffusion/reaction model is operational and it enables one to predict the oxidation level and the thickness of the oxidized surface layer in massive samples before first crack appearance. For a dedicated material, this model requires to carry out a high number of aging tests on thin films and massive samples for model parameters identification and validation. All these tests have been done on the materials studied within the COMPTINN' program.

Effects induced by the Thermo-Oxidation on physico-chemical and mechanical properties of the matrix are also well understood and modelled. The elastic modulus variation linked to polymer oxidation is selected as a good indicator of the polymer oxidation. A phenomenological correlation is found between the elastic modulus and the concentration of oxidation products mainly resulting from the chain scission process (i.e. carbonyl groups). This correlation can be kinetically justified. However, this direct link between chemical modifications and mechanical properties modifications is still to be clearly defined for all polymer matrices. This oxidation indicator is also coupled with the appearance of fibre/matrix de-cohesion. This should allow us to the elaboration of an initiation criterion for fibre/matrix debonding.

Even if the understanding and modelling of the oxidation phenomena at the small scales reach a satisfactory level, upscaling towards the prediction of the structural behaviour under oxidation and mechanical loading is still a challenge. Some preliminary results introducing the effects of oxidation into a mesoscale modelling strategy were obtained in this program, however a number of critical points remain. The understanding of the coupled effect of thermo-oxidation and mechanical loading is still a critical point for durability prediction at the structural scale. A new oxi-delamination test has been developed to study the propagation of delamination under external loading with oxidative environment, but further work is still needed to identify all involved mechanisms. The final objective of this new test is the identification of the evolution of the strain energy release rate at the mesoscopic scale versus the oxidation level of the sample (identified through the diffusion/reaction model).

\section{Acknowledgements}

The authors would like to acknowledge the French FUI (Fond Unifiés Interministériels) for financial support to the project COMPTINN.

\section{References}

Bellenger, V. and Verdu, J. (1985), “Oxidative skeleton breaking in epoxy-amine networks", J. Appl. Polym. Sci., 30, 363-375.

Bowles, K.J., Jayne, D. and Leonhardt, T. (1993), "Isothermal aging effects on PMR-15 resin", SAMPE Quarterly, 2-9.

Bowles, K.J., Papadopoulos, D., Inghram, L., McCorkle, L. and Klan, O.V. (2001), "Long- time durability of PMR15 matrix polymer at 204, 260, 288, and 316 C", NASA/TM-2001-210602, 2001 Research repport. 
Celina, M.C., Dayile, A.R. and Quintana, A. (2013), “A perspective on the inherent oxidation sensitivity of epoxy materials", Polymer, 54(13), 3290-3296.

Chocinski-Arnault, L., Olivier, L. and Lafarie-Frenot, M.C. (2009), "Effects of thermal oxidation on an epoxy-amine thermoset studied by mechanical spectroscopy", Mater. Sci. Eng., A, 521-522, 287-290.

Colin, X. and Verdu, J. (2005), "Strategy for studying thermal oxidation of organic matrix composites", Compos. Sci. Tech., 65, 411-419.

Colin, X., Marais, C. and Verdu, J. (2001), "A new method for predicting the thermal oxidation of thermoset matrices: application to an amine crosslinked epoxy", Polym. Test., 20(7), 795-803.

Colin, X., Mavel, A., Marais, C. and Verdu, J. (2005), "Interaction between cracking and oxidation in organic matrix composites", J. Compos. Mater., 39(15), 1371-1389.

Daghia, F. and Cluzel, C. (2013), "An oxidation/delamination test for laminated composites with organic matrix", JNC 18, Nantes, France, June.

Daghia, F. and Cluzel, C. (2014), "Experimental study of the propagation of delamination under oxidizing environment and mechanical loading", ECCM 16, Seville, Spain, June.

Daghia, F., Zhang, F., Cluzel, C. and Ladevèze, P. (2015), “Thermo-mechano-oxidative behavior at the ply's scale: the effect of oxidation on transverse cracking in carbon-epoxy composites", Compos. struct., 134, 602-612.

Dole, P. and Chauchard, J. (1995), "Determination of oxidation profiles of elastomeric materials. Part I. Microscopic approach: pinpoint DMA", Polym. Degrad. Stab., 47(3), 441-448.

Gigliotti, M., Olivier, L., Vu, D.Q., Grandidier, J.C. and Lafarie-Frenot, M.C. (2011), "Local shrinkage and stress induced by thermo-oxidation in composite materials at high temperatures", J. Mech. Phys. Solid., 59(3), 696-712.

Hairer, E. and Wanner, G. (1996), Stiff and Differential-Algebraic Problems, Series In Computational Mathematics, Springer, Berlin, Germany.

Johnson, L.L., Eby, R.K. and Meador, M.A.B. (2003), "Investigation of oxidation profile in PMR-15 polyimide using atomic force microscope (AFM)", Polym., 44(1), 187-197.

Ladevèze, P. and Lubineau, G. (2002), "An enhanced mesomodel for laminates based on micromechanics", Compos. Sci. Tech., 62(4), 533-541.

Ladevèze, P. and Lubineau, G. (2002), "On a damage mesomodel for laminates: micro-meso relationships, possibilities and limits”, Compos. Sci. Tech., 61(15), 2149-2158.

Ladevèze, P., Daghia, F., Abisset, E. and Le Mauff, C. (2014), "A micromechanics- based interface mesomodel for virtual testing of laminated composites", Adv. Model. Simul. Eng. Sci., 1(1), 1-16.

Lafarie-Frenot, M.C., Rouquie, S., Ho, N.Q. and Bellenger, V. (2006), "Comparison of damage development in C/epoxy laminates during isothermal aging or thermal cycling", Compos. Part A: Appl. Sci. Manuf., 37(4), 662-671.

Lafarie-Frenot, M.C., Grandidier, J.C., Gigliotti, M., Olivier, L., Colin, X., Verdu, J. and Cinquin, J. (2010), "Thermo-oxidation behaviour of composite materials at high temperatures: A review of research activities carried out within the COMEDI program", Polym. Degrad. Stab., 95(6), 965-974.

Lubineau, G. and Ladevèze, P. (2008), "Construction of a micromechanics-based intralaminar mesomodel, and illustrations in ABAQUS/Standard", Comput. Mater. Sci., 43(1), 137-145.

Lubineau, G., Violeau, D. and Ladevèze, P. (2009), "Illustrations of a microdamage model for laminates under oxidizing thermal cycling", Compos. Sci. Tech., 69(1), 3-9

Minervino, M., Gigliotti, M., Lafarie-Frenot, M.C. and Grandidier, J.C. (2013), "The effect of thermooxidation on the mechanical behaviour of polymer epoxy materials", Polym. Test., 32(6), 1020-1028.

Minervino, M., Gigliotti, M., Lafarie-Frenot, M.C. and Grandidier, J.C. (2014), "A coupled experimental/numerical approach for the modelling of the local mechanical behaviour of epoxy polymer materials", J. Mech. Phys. Solid., 67, 129-151.

Nettles, A.T., Gregory, E.D. and Jackson, J.R. (2007), "Using the climbing drum peel (CDP) test to obtain a GIC value for core/face sheet bonds", J. Compos. Mater., 41, 2863-2876

Olivier, L. (2008), "Prévision du vieillissement thermo-oxydant de composites à matrice organique dédiés à l'aéronautique : prise en compte des couplages multi-physiques", PhD Dissertation, University of Poitiers, 
France.

Olivier, L., Ho, N.Q., Grandidier, J.C. and Lafarie-Frenot, M.C. (2008), "Characterization by ultra-micro indentation of an oxidized epoxy polymer: correlation with the predictions of a kinetic model of oxidation", Polym. Degrad. Stab., 93(2), 489-497.

Putthanarat, S., Tandon, G.P. and Schoeppner, G.A. (2007), "Influence of polishing time on thermooxidation characterization of isothermally aged PMR-15 resin", Polym. Degrad. Stab., 92(11), 2110-2120.

Putthanarat, S., Tandon, G.P. and Schoeppner, G.A. (2008), "Influence of aging temperature, time, and environment on thermo-oxidative behaviour of PMR-15: nanomechanical characterization", J. Mater. Sci., 43(20), 6714-6723.

Rasoldier, N., Colin, X., Verdu, J., Bocquet, M., Olivier, L., Chocinski-Arnault, L. and Lafarie-Frenot, M.C. (2008), "Model systems for thermo-oxidised epoxy composite matrices", Compos. Part A: Appl. Sci. Manuf., 39(9), 1522-1529.

Schoeppner, G.A., Tandon, G.P. and Ripberger, E.R. (2007), "Anisotropic oxidation and weight loss in PMR-15 composites", Compos. Part A: Appl. Sci. Manuf., 38(3), 890-904.

Tandon, G.P., Pochiraju, K.V. and Schoeppner, G.A. (2006), "Modelling of oxidative development in PMR15 resin", Polym. Degrad. Stab., 91(8), 1861-1869.

Terekhina, S., Mille, M., Fayolle, B. and Colin, X. (2013), "Oxidation induced changes in viscoelastic properties of a thermostable epoxy matrix”, Polym. Sci., Series A, 55(10), 614-624.

Vu, D.Q., Gigliotti, M. and Lafarie-Frenot, M.C. (2012), "Experimental characterization of thermooxidation-induced shrinkage and damage in polymer-matrix composites", Compos. Part A: Appl. Sci. Manuf., 43(4), 577-586. 